\title{
THE INTEGRATION EXPERIENCES OF YOUNG GHANAIAN-BORN WOMEN IN TORONTO
}

by

Winnifred Nketiah, BSW, Ryerson University, 2014

\author{
An MRP \\ presented to Ryerson University \\ in partial fulfillment of the \\ requirements for the degree of \\ Master of Social Work \\ in the Program of \\ Social Work
}

Toronto, Ontario, Canada, 2016

(C) Winnifred Nketiah 2016 


\section{AUTHOR'S DECLARATION FOR ELECTRONIC SUBMISSION OF A MRP}

I hereby declare that I am the sole author of this MRP. This is a true copy of the MRP, including any required final revisions.

I authorize Ryerson University to lend this MRP to other institutions or individuals for the purpose of scholarly research

I further authorize Ryerson University to reproduce this MRP by photocopying or by other means, in total or in part, at the request of other institutions or individuals for the purpose of scholarly research.

I understand that my MRP may be made electronically available to the public. 


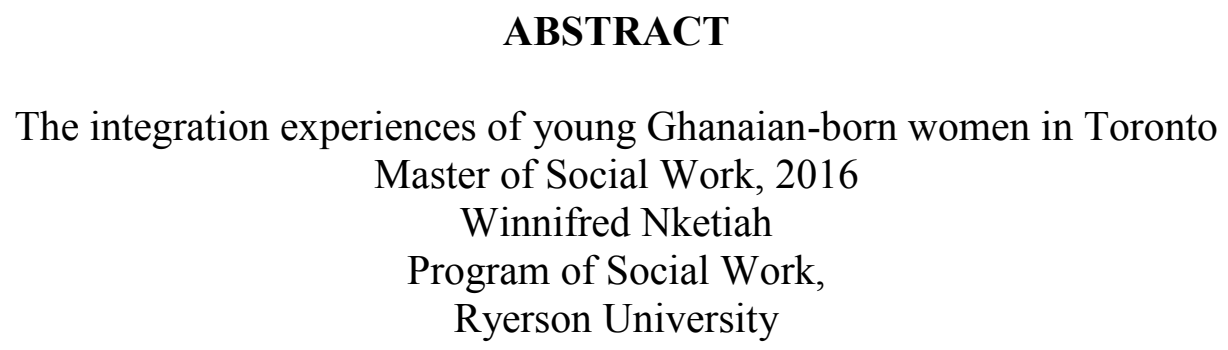

This study examines the trajectories and meaning-making of transnationalism for Ghanaian-born young women living in Toronto--a population often silenced and/or categorized within other identities (Tettey \& Pampulampu, 2005; Wong, 2000; Yesuf, 2005). This investigation highlights how family, gender, race, and culture inform cross-bordering. Narratives of three Ghanaian-born females living in Brampton identify how Ghanaian-born women understand what it means to be both Ghanaian and Canadian, and explore how gender, race and culture may inform these understandings. Lastly, this study considers whether the intersection of gender, race and culture complicate Ghanaian female identity. This research illustrates that socio-political circumstances in their country of origin and in Canada shape the women's experiences, life goals and overall practices. In exploring the complexities associated with how gender, culture and race influence identity formation, this research suggests that Ghanaian-born women are constantly renegotiating and redefining their hyphenated-identities, and their place within Ghana and Canada.

Keywords: Ghanaian-Canadian women, Ghanaian-born, transnational/multiple identities, migration, African-Canadian women. 


\section{ACKNOWLEDGEMENTS}

First I would like to thank my supervisor, Professor Susan Preston whose encouragement, comments, critiques and suggestions have made this project a reality. Your support throughout my master's thesis is greatly appreciated.

Secondly, I would like to thank my Ghanaian community in Toronto, and the participants of this study. Finally, I would like to thank the entire Social Work Faculty for all your support and patience throughout my journey. 


\section{DEDICATION}

This project to dedicated to all young Ghanaian-born women, and their daughters, and their daughters-daughters. It is dedicated to our struggle. I also dedicate this project to the ones who kept me motivated, my husband and children. 


\section{TABLE OF CONTENTS}

Chapter 1

Chapter 2

Chpater 3

Chapter 4

Chapter 5

Chapter 6

Chapter 7

Appendices

Reference List
Page 1

Page 7

Page 16

Page 27

Page 47

Page 65

Page 93

Page 95

Page 105 


\section{LIST OF APPENDICES}

Appendix A - Recruitment Text for Ad and Flyers $\quad$ Page 95

Appendix B - Email to Community Organizations and Post-secondary Institutions Page 96

$\begin{array}{ll}\text { Appendix C - Demographic Questions } & \text { Page } 97\end{array}$

$\begin{array}{ll}\text { Appendix D -Interview Guide } & \text { Page } 99\end{array}$

$\begin{array}{ll}\text { Appendix E- Consent Form } & \text { Page } 101\end{array}$

$\begin{array}{ll}\text { Appendix F - Counselling and Community Resources } & \text { Page } 105\end{array}$ 


\section{CHAPTER ONE: INTRODUCTION}

I begin this project as an attempt to understand my community better. My entry point in this discussion is as a half-Ashanti ${ }^{1}$, half-Fante ${ }^{2}$ young woman who has spent the majority of her life (roughly 25 years) in Canada, specifically in the Toronto area. Although the Ghanaian population has seen dramatic growth and is on the incline, there has been and continues to be an underrepresentation and misrepresentation of Ghanaian identities by the Canadian government and Canadian society. Ghanaians have been present within the Canadian landscape as early as the 1970's due to the Trudeau government's initiative to open the Canadian borders for labour market purposes (Opoku-Dapaah, 1998). Yet still, Ghanaians find themselves severely underrepresented in all aspects of Canadian life. Currently, there is a large influx of new immigrants within Ghanaian youth population, who find themselves struggling to negotiate the social, cultural and political spaces of two-worlds - Ghana and Canada. Thus, because of the increase in the youth population and underrepresentation of Ghanaian identity in popular discourse, it is important to examine and have a critical understanding of how such spaces contribute to the transnational identity formation of Ghanaian youth. As a local community activist and a young feminist, my area of interest is regarding young Ghanaian women, particularly Ghanaian-born women currently living in the Diaspora (Toronto). This group, I argue has been severely undervalued and unrecognized in many Canadian spheres. Many scholars have studied continental-African bodies within the Canadian landscape, and have provided research that speaks to the nuanced realities of life in Canada (Agyekum 2012; Baffoe 2010; Manuh, 2005; Mensah, 2002; Tettey \& Puplampu 2005; Wong, 2006; Yesufu 2005). Yet

\footnotetext{
1 The Ashanti tribe is the dominant group in Ghana, and was responsible for the revolt against the British Empire in the 1900's.

2 The Fante tribe is a dominant subgroup within Ghana located in the south-western coastal region of Ghana.
} 
still, even within such scholarship, I argue that the realities of Ghanaian women and young girls are rarely ever documented.

It is with this in mind, that I undertake this project and seek to consider how Ghanaianborn women conceptualize and negotiate their hybrid identities and/or challenge notions of Africanness, Canadianness and womanhood. In Massaquoi's An Unsettled Feminist Discourse (2007), she makes an critical case for an African-centred feminism that "understands the Diaspora as definitionally-ambiguous [in terms of definition, not methodology] but, also understands that we [African feminists scholars] must reconnect with Africa and make it central to this definition of feminism" (p. 34). Like Massaquoi, I am interested in creating a space for feminist projects that situate African women within a Canadian landscape that considers the diversity amongst Black women's historical entry points into the Canadian state. My aim as a feminist academic is that I may contribute to a growing body of knowledge on Africandescended women in Canada, through an African feminist lens.

Contemporary social work involves a highly political process, and is often discussed through the lens of challenging systems of oppression and domination, and involves examining issues through an intersectional lens (Baines, 2011). In fact, modern day social work is about doing anti-oppressive social work. As a self-proclaimed anti-oppressive and feminist social worker, my core interest has always been the lives of immigrant women and in particular, women of the African Diaspora. Although often defined collectively as immigrant women, and/or Black women, it is important to acknowledge that this population is not homogenous, as evidenced in the works of Kitson (2003), Massaquoi (2007), Okeke-Ihejirika and Spitzer (2005) and Tettey and Puplampu (2006). Women immigrate to Canada from all over the world and occupy various social locations (such as race, ethnicity, class, ability and sexual orientation). 
Such criteria intersect with marital status, family composition, religious affiliation, language, level of education, and social support systems. As a result, immigrant women differentially experience immigration, often experiencing discrimination, which leads to various forms of oppression and marginalization. My rationale for selecting this topic stems from personal experience of migration as a child and as a frontline service provider struggling to meet the multiple needs of the communities I serve. Through my personal and professional experience, I have found that the general Canadian system does little to address the structural determinants of the everyday realities of African-Canadian women, specifically Ghanaian-born women. Adequate research is required in this area in order to understand these women's experiences and to improve and develop culturally appropriate services.

Thus, my area of focus is to investigate and interrogate the difficulties some Black Ghanaian-born women experience in their attempts to integrate into Canadian society. When considering the Black Canadian female experience, there is a strong focus, at times unintentional, on Afro-Caribbean and American feminist writers and lived-experiences as articulated by many continental African scholars (Kitson, 2003; Tettey \& Puplamu, 2005; Wane, 2007; Yesufu, 2005). This Caribbeanization (Tettey \& Puplampu, 2006) I argue has resulted in a silencing of crucial African-feminist voices and experiences. In fact, African-Canadian women are misrepresented and under-represented—both in academia and popular culture (Owusu, 2006). This under-representation, I believe, has resulted in the homogenization of our experiences under the umbrella of women of colour and/or African-American (Blay, 2008; Kitson, 2003; Mekgwe, 2007; Owusu 1999). In their studies of Ghanaian-Canadian women living in Toronto and Edmonton, Baffoe (2010), Wong (2003) and Yesufu (2005) articulate that among all immigrant populations, African women are underrepresented in the field of research studies because they 
are often consider within the category of Black women. But I argue that this juxtaposition of African women and Black women as being homogeneous erases African women of their identity and experience, and creates a false sense of community.

More than anything, this project seeks to illustrate how knowledge is constructed around the discourse of African-Canadian women's experience. Along with this, I explore the paradigms such knowledge exists within and whose voices are heard and/or silenced within the existing knowledge. The purpose here is to reflect and critically engage with existing literature/research studies on the lived-experiences of continental African-Canadian women. The aim is also to provide a critical narrative of the theoretical understanding and meaning-making around their experiences and identity.

\section{Conceptual Background}

The realities of African-Canadian women are as unique and diverse as are their identities. With this in mind, this project is about making a substantial contribution toward the understanding of social life for Ghanaian-born women in Canada. As indicated earlier, this body of work is also about providing a voice and a counter-narrative to the underrepresentation and the essentialist nature of Africa women's identity. With an understanding of the complexity of identity, I undertake this project with some critical knowledge of the power of language. While I start with a base identity of Ghanaian-born women, this is in no way an attempt to limit and/or homogenize their experience. Rather it is the recognition that there are differences (somewhat vast) between Ghanaian-born youth and their Canadian-born counterparts. It is also an attempt to illustrate that Ghanaian-born youth occupy a position of belonging to two (or more) cultures. The language of Ghanaian-born, then, reflects this divided diasporic consciousness. Originally, I adopted the notion of "Ghanaian-Canadian" women; however, I was challenged (through closer 
analysis of my data) to reconsider this notion because I recognize its exclusionary nature. What about the experiences of Ghanaian-born (women) refugees, permanent residents and/or asylumseekers? What about those individuals and identities whose narratives never get told because of their status or lack of status? For such reasons, I decided to use the concept of Ghanaian-born. Further, my use of the term "1.5 generation" (1.5geners) borrows from Rumbuat (1991) and refer to individuals who were born in their home country, and educated in a host country-specifically those who were ten-years of age or below when they immigrated to Canada. First generation (first geners) refers to individuals who migrated here between the ages of 12-26 years of age. The common use of the term "first-generation" refers to the children of immigrant parents who have been raised, for the majority of their lives, in the host country (Manuh, 2005; OpokuDapaah, 2006; Owusu, 2006; Wong, 2000). For the purposes of this study, my use of firstgeneration will always refer to the Ghanaian-born children of Ghanaian immigrants in Canada. I explore these concepts further in Chapter 4. Next, the linguistic origin of "Diaspora" comes from the Greek term for "dispersal" or "scattering of peoples" as per Webster's Dictionary (Merriam-Webster, 2003). While Diaspora has been most popularly used in the context of the Jewish Diaspora, in reality, for various political reasons including slavery, colonialism, forced migration and conflict, there exist many Diasporas in the world today. For the purposes of this project, my use of the term Diaspora will always refer to the African Diaspora(s), specifically in Canada, unless stated otherwise. My use of the term "identity" within this project borrows from African-Diasporic writers Wisdom Tettey and Korbla Puplampu (2006), who posit that there are two related aspects of identity: subjectivity and (em)power(ment) - understood as meaningmaking and self-defining characteristics that individuals assign themselves. Finally, my use of the term transnational/ism refers to Owusu (2006) - in that transnational/ism refers "to the web of 
cultural, social, economic, and political relationships, practices, and identities built by immigrants across national borders" (p. 2).

This project has three main objectives. Firstly, through an exploration of the realities of Ghanaian-born women and their identity formation, I seek to challenge popular discourse about what it means to be Black in Canada - which I argue has historically privileged Afro-Caribbean bodies as the primary Black communities in Canada. Secondly, I undertake this project as an attempt to analyze my own community's current socio-political concerns in Canada, particularly young women's struggles with identity within a larger Euro-patriarchal Canadian society, as well as their own family's cultural expectations of Ghanaian womanhood. Lastly, I attempt to situate some of the issues within three distinct yet complimentary frameworks: Critical-race theory, Black-feminist thought and African Diasporic feminist politic.

What follows is that I present fifteen recent research studies by prominent African scholars (as it relates to the African-Canadian experience). Through this literature review in Chapter Two and what follows in Chapter Three, I present how an African feminist theoretical framework is vital to such an investigation. I present my research questions and situate them within a contemporary framework. Chapter Four focuses on the method of Grounded theory and Narrative Analysis, in my attempt to help contribute to constructive theoretical development and understand how Ghanaian-born women traverse through their hybrid worlds. I then offer the findings of my thematic analysis of the participant interviews, in Chapter Five. In Chapter Six I discuss these findings within the context of current scholarship and my theoretical framework. This MRP ends with a concluding Chapter Seven, where I summarize the key points and recommendations from this inquiry. 


\section{CHAPTER TWO: LITERATURE REVIEW}

For the purpose of this project, my point of reference draws from Critical-race theory (CRT), Black Feminist Thought and African/Diasporic Feminist analysis (Massaquoi 2007; Timothy, 2007). As a feminist woman of colour, my personal is always guided by my political and my political by my personal. In fact, Massaquoi (2007) reminds us that our "experience and practice should push theory to explain our everyday life and experience" (p. 13), and not visaversa. In examining our experiences in relation to our social location/subjectivity, we can become better advocates, service-providers and educators. Thus, my analysis of interrogating dominant discourses around the identities of Ghanaian-born women stems out of years of frustration and exposure to inaccurate, and at times inappropriate, literature and beliefs around our identity. Tettey and Puplampu (2005), argue that against the backdrop of Caribbean and Black American women, the experiences/identities of African-women have been "lost data describing the experiences of women of colour" (p. 34). This misrepresentation and underrepresentation within the school system, popular literature and general Canadian populace, I argue, has led to years of silencing, one which renders our identities/experiences non-existent and meaningless.

Throughout my practice and studies of social work, I have encountered many gaps within feminist discourse and social work pedagogy about the Black female experience. Prominent discussion of Black women has centred on the work and issues raised by Black American feminists. This, of course, is a very particular location that, while in some ways is reflective of the general Black female experience post-colonization, in other ways does not respect the nuances of various African female scholarship and identities throughout the Diaspora. 


\section{Review and Critique of Existing Literature}

Yet still, I cannot ignore the existence of some recent literature and scholars who have successfully and unapologetically chronicled the lived-realities of African-Canadian women, and more specifically the Ghanaian-Canadian community. Such important works include Baffoe (2010) Cudjoe (2005) Dei (1997), Kumsa (2005), Okeke-Ihejirika and Spitzer (2005), Owusu (2006) Tettey and Puplampu (2005), Wong (2000); and Yesufu (2005). It is important to note that many of the scholars I have chosen here are native Ghanaians and/or hail from the continent. This is intentional, as I believe it is important to introduce literature and knowledge from indigenous writers (Reyes-Cruz, 2008), and also to highlight subjugated knowledge--that is "historical knowledge which has always been present, but disguised and buried" (Foucault, 1980: p. 110). This is particularly important because it interrupts the key stakeholders of knowledge re/production.

Historically, racialized women have been constructed as consumers of knowledge rather than producers of knowledge (Reyez-Cruz, 2008; Schreiber, 2000). The lived experiences and worldviews of racialized women have not been considered legitimate forms of research knowledge; rather, they have served as informal folklore (Landson-Billings, 2003). But, research on African women in gender studies has grown substantially to a position where Africancentered gender theories and praxis contribute to theorizing on global feminist scholarship. But this has not always been the reality. In fact, contemporary notions of African women are born out of white-supremacist-patriarchal European conceptualization of African-ness and Blackness (Crenshaw, 1996 ; Hill-Collins, 1999). The knowledge constructed around our identity has been fabricated and brewed in a Western, European pot. This knowledge has been dismissive, abusive, and downright inappropriate. Due to the continual recovery and reconceptualising of identity, the 
position of continental African women as transmitters of knowledge has been traditionally devoid in literature. Although our voices have been traditionally excluded from knowledge construction, as more African female scholars begin to engage in exploring our experiences, we are now beginning to unload this "intellectual marginalization" (Tettey \& Paplampu, 2005, p. 17) and misrepresentations. The studies in the proceeding discussion address the complex and interlocking conditions that impact African women's lives and reproduction of oppression, opportunity and privilege, and attempt to understand the history, social constructions and features that have shaped their history within the Canadian landscape.

With that said, the existing literature on the Ghanaian-Canadian community is not without its limitations - it gives voice to older generations (Yesufu, 2005), educational aspirations of youth (Cudjoe, 2005; Dei, 1997; Wane, 2007), employment and economic equity (Manuh, 2000; Wong, 2000), immigration/settlement (Baffoe, 2009; Kumsa, 2005; Yesufu, 2005 ) and identity construction (Massaquoi 2007; Okeke-Ihejirika \&Spitzer, 2005; Owusu, 2006; Tettey \& Paplampu, 2005). I will explore this further later. Though these studies provide a valuable contrition to the difficulties some Africans experience in Canada, what I find missing in their analyses are the nuanced ways in which Africans traverse through the geo-political and socio-political climate in Canada. Further these studies are still missing much of the picture as they tend to borrow from American scholars both in conceptual background and theoretical frameworks.

Prominent discussion of African women has primarily centred on the scholarships noted above, which focus on the transnational patterns of Africans. Yesufu (2005) studied the integration and adaptation of African immigrant youth in Edmonton. Her study focuses on reconstructing and deconstructing African identity, and does this through qualitative methods - 
primarily open-ended interviewing and focus groups, Yesufu using anti-racist and anti-colonial epistemological approaches to guide her research. In their studies, Okeke-Ihejinka and Spitzer (2005) and Tettey and Puplampu (2005) focus on the ways in which African women are homogenized with Caribbean women and other communities. These two studies highlight how African women occupy different subject locations at different moments. Both studies use qualitative methods of interviews and focus groups. Of all the studies reviewed, Okeke-Ihejinka and Spitzer (2005) is the one of the only studies which uses a theoretical paradigm which operates from the authentic African approach. Baffoe (2009) and Kumsa (2005) study the renegotiation of meaning, and the reconstruction of the concept of home. While the former focuses on children of Ghanaian immigrants, and uses an ethnographic approach, the latter reconstructs the narratives of identity of the Oromo (Ethiopian ethnic group) community in Edmonton. Both these studies use personal interviews and focus groups as a method of data collection.

Notably, Cudjoe (2005), Dei (1997) and Wane (2007) critically interrogate the educational system and look at the learning experiences of African and Black students within the Canadian curriculum, specifically in Edmonton and Toronto. While Dei's (1997) research contests for inclusion and diversity within the Canadian curriculum, both Cudjoe (2005) and Wane (2007) advocate for better pedagogy and the incorporation of indigenous and Africancentred knowledge and epistemologies. With the exception of Dei's (1997) study, these studies fail to provide tangible solutions of what such inclusion and representation would look like.

Wong's (2000) study of the employment and economic equity of African women in Toronto uses interviews and focus groups to gather information about ways in which Ghanaian women become disenfranchised in the labour market in Edmonton. She adopts a gendered 
analysis of ways in which the Canadian systems works to further marginal women of color. However what is missing is an intergenerational analysis to understand the ways in which children of immigrants experience employment and economic equity differently from their parents. Wong (2000) also situates and interprets the data within larger contexts, as opposed to making it unique to the experiences of the participants. Next, the majority of the studies are conducted in major Canadian cities (Toronto, Edmonton, and Vancouver). While this may be a result of researcher's location and interest, it does little to address the Ghanaian population living outside of these cosmopolitans. One can argue that such metropolises are most popular amongst researchers because it reflects where the community is mostly represented. And although my own research is situated in a large city (Toronto/Brampton), I also stress for future research within smaller rural African communities, because their struggles and challenges may or may not look entirely different. Lastly the studies on identity construction (Okeke-Ihejirika \& Spitzer, 2005; Owusu, 2006; Tettey \& Peplampu, 2005) discuss well the ways in which Africans experience their Africanness different from each other. Okeke-Ihejirika and Spitzer (2005) in particular note the unique experiences of African youth in Canada, as they struggle between their multiple identities. However, this study fails to explore ways in which historical circumstances (such as the case of war-torn refugees) influence adaptation processes and youth identity.

The aforementioned scholarship provides generalized accounts of the Ghanaian experience within Canada, and focus on conventional research that draws from well-known and well-established theories about race and gender, and that does not acknowledge the uniqueness of the African experience. With the exception of Kumsa (2005) and Okeke-Ihejirika and Spitzer (2005), the literature ignores indigenous theoretical frameworks and paradigms. Of the seven studies reviewed, five of them used anti-racist and anti-colonial as units of analysis. And while 
these are very important and relevant to any analysis about continental persons, it does not speak to their current socio-political lives, as many struggle with identity in the face of multiculturalism. For example, Africans living on the continent did not experience the TransAtlantic Slave-trade much in the same vein as those who were violently uprooted into the Americas and elsewhere. However, dominant discourse about African slavery often lumps continental-Africans and people of African-descent all in the same category. Additionally, adopting a solely anti-colonial analysis assumes that we navigate and experience blackness in the diaspora in the same way.

Secondly, the gendered implications of identity - that is, the ways in which young Ghanaian men experience identity different from young Ghanaian women - is missing from much of the research. What I am proposing is an analysis which stems from an African feminist theoretical standpoint, and focuses on the transnational identities and experiences of young Ghanaian-born women. In hopes to reconstruct and deconstruct identities, this project is informed by African feminist analysis because such an analysis can openly provide a platform for the voiceless and bring life to their stories/experiences. Research on identity construction and gender is very necessary within African communities in the Diaspora; it is through such inquiries that continental Africans can stand up against mainstream, grandeur historical accounts and homogenized notions of Blackness and/or African-ness.

It is with this in mind that I take on this project as a break away from the conventional way of "researching on or about" immigrant identity and seek to introduce an African feminist discourse of "studying with" individuals, similar to the notion of partnering with research participants by "researching with" (Heron \& Reason, 2006). While this study was not a participatory partnership with participants active throughout the research process, I was resisting 
other mainstream research practices that used dominant theories and paradigms to inform the research process, as a way to resist the practices of "researching on or about". Potts and Brown (2005) note that research is about "building relationships and seeking answers" (p. 257). As a result, social work research should seek to work with participants/communities to identity methods of intervention to social problems. These concepts provide a guideline for ensuring that my work as a social work researcher is liberating and provides consciousness-raising for the participants. The political and resistance-nature of feminist research suggests that the research process should address issues that are of fundamental importance to participants, and place ownership of knowledge back into the hands of those who experience it (Henry, 2007). For me, this simply means advocating for community-based goals of self-determination of the participants. The purpose here is to enhance critical-consciousness through engaging and collaborating with the participants, and getting them involved in identifying their needs through narrative story, with the hope that this research will help to build the knowledge base to enhance and develop sustainable programmes and initiatives in the community.

In the world of research, knowledge is power. And the more the researcher knows/understands about a community (albeit outside of collecting data), the more authentic and rewarding the research will be. Schreiber (2000) suggests that "cultural knowledge originates from a culture's center"; therefore, research must be concerned with the "ideals, values and history" of any interrogation of a culture (p. 47). In fact, Schreiber explores an Afrocentric paradigm and provides a good analysis of the use of dominant discourse in relation to marginalized groups, and notes that the use of dominant Western and European perspectives to investigate non-Western/European cultures "results in inaccurate, misleading, and biased interpretations" (Schreiber, 2000, p. 656). In response, some scholars contend that the lack of 
indigenous knowledge within academia (research) is intentional and results in "intellectual marginalization" (Tettey \& Puplampu, 2006, p.83). Like Schreiber (2000), Reyes-Cruz (2008) also notes that research should be from the margins and attempt to integrate indigenous paradigms, particularly when conducting studies with marginalized communities - because indigenous paradigms provide a "political process to rediscover knowledge....and challenge the status quo" (Potts \& Brown, 2005, p. 261).

The above discussion illustrates the leading voices within research around Ghanaian identity within Canada. While the focus on Ghanaian-centred knowledge and African-centred theory is valuable, the existing literature illustrates a Ghanaian identity solely belonging to participants within the labour market (Wong, 2000; Yesufu, 2005) and the academic realm (Cudjoe, 2005; Dei, 1997; Wane, 2007). This is problematic as it represents an identity that is solely tied to those who are documented as having status within government categorizations and definitions. The literature does little to highlight gender and citizenship, notably the difference in the experiences of Ghanaians who possess Canadian citizenship and non-status Ghanaians. Although some of the literature highlights the educational and labour market engagement of youth, it ignores the importance and difference between the experiences of Ghanaian-born youth and their Canadian-born counterparts. And it is from this point that I endeavour to pick up my research to highlight the complexities some Ghanaian-born females experience when migrating as a child/teen as opposed to the difficulties experienced as an adult with and without status. And while Canadian-born Ghanaian females also experience identity issues, this research is focused on transnational identities, that is, the ways in which some (Ghanaian) women negotiate their identities away from their homeland.

In the next chapter, I discuss the theoretical frameworks used to gather, interpret and 
analyze the data as it relates to detailed aspects of migration and transnational experiences. Specifically, I look at Black feminist thought, Critical-race theory and African Diasporic feminism, and seek the ways in which these paradigms can be used as tools to examine the current lived-realities of Ghanaian-born young women. 


\section{CHAPTER THREE: THEORETICAL FRAMEWORK}

One consequence of the inflexibility of differentiation [in African Diaspora scholarship] is the scant attention paid to continental Africans as an autonomous focus of academic inquiry. Unlike Asian or Caribbean immigrants in Canada about whom there is quite an appreciable amount of literature, continental Africans have generally not been the specific focus of many research endeavours. It is worth noting that this intellectual marginalization has occurred in the United States, as well...In her analysis of the literature on Black Africans in the United States, Halter, for example, notes the inflexibility of census data collection patterns in differentiating among the contemporary Black American population. She contends that research on the country's Black population tends to privilege the "Americanity of the research cohort", or it overly focuses on the inmigration patterns of people from English- and Spanish-speaking Caribbean countries.

(Tettey \& Puplampu, 2005, p.5)

I began this project with the sole intention of adopting a theoretical paradigm which focuses mainly on the epistemologies of African women. Initially, I wanted to resist the use of popular frameworks such as Black feminist thought and Critical-race theory (CRT), which homogenize the experiences of African women and Black-American women--theories which propose to commit the very offense I am arguing in this project. However, the further I entered into this research, the more I realized that my analysis is more than one dimensional, and I could not do justice to this body of work without incorporating Black feminist perspective and CRT. Although the main analysis adopts an African Diasporic feminist perspective, it also borrows from CRT and Black feminist perspective, because continental African women exist and operate within the same white-supremacist system, as do Black/Caribbean Canadian women. As a result, it is important to provide an analysis that situates their current socio-political atmosphere, while considering their historical context and journey. As such, I enter this discussion of Ghanaianborn women from a Black feminist thought, CRT and African Diasporic feminist praxis. The proceeding section will provide an in-depth analysis of the aforementioned paradigms.

But before I commence, I want to first discuss the current lived-reality of the continental African woman. Certainly, the over-emphasis on particular communities (Caribbean and 
African-American) in the Diaspora has worked to limit and underestimate the contributions and realities of continental Africans in the west. Nonetheless, with cross-border migration trends and processes, Africans in the Diaspora seek to change and grow in ways which contradict the homogenizing identity placed on them. Yet still, several scholars, politicians, and community "gatekeepers" have made the error of universalizing notions of Africanness, Blackness and Diaspora (Tettey \& Puplampu, 2005). Many scholars have noted the histories of continental African communities in Canada are often subsumed under an overarching category of Black (Massaquoi, 2007; Okek-Ihejirika \& Spitzer, 2005; Wane, 2007; Yesufu, 2005). To understand the realities of African-descendent communities in the diaspora, then requires a holistic approach, one that recognizes and celebrates the uniqueness and authenticity of the diverse socio-political processes that each African community faces.

It is a result of the aforementioned discussion that I enter this research from a CRT, Black-Feminist thought and African Diasporic feminist perspective. The following is an in-depth look into the history and foundations of each paradigm, and its place within this inquiry. The theories used here provide an important backdrop to some of the existing knowledge and views on African women in the diaspora (Agyekum, 2012; Manuh, 2000; Opoku-Dapaah 2006; Owusu 2006; Wong 2000). Along with this, CRT, Black-Feminist thought and African-Diasporic feminism all provide an African-centered perspective, which in the words of Molefi Kete Asante (1998), means "literally placing African ideals at the center of any analysis that involves African culture and behavior" (p. 6). And as an African feminist researcher, I have a duty to develop knowledge that is culturally and historically specific and articulated.

Black feminist thought is born out of the Black Liberation movements in the United States in the early 1950's to end racial segregation and discrimination. The Movement was 
characterized and popularized by religious community leaders, who were often male. Such movements have been criticized for being gender-neutral (in essence, it ignored the struggles and oppression of the black women). The male leaders of the Civil Rights Era failed to acknowledge the multiple stages of oppression experienced within the black community; this, in turn, resulted in a generalization and homogenizing of the Black experience/identity/culture. Failure to extend the liberation to women understandably created angst and tension within the black community and among black women scholars such as Wallace (1979), and Hill-Collins (1997) and hooks (1990) in later years. Thus, Black feminist thought as articulated by Patricia Hill-Collins, consists of ideas created by Black women that clarify a standpoint of and for Black women. Within this, Hills-Collins notes that Black-feminist theory is about the Black woman's perspective/voice for Black women. It is about "self-definition, self-valuation," (Hill-Collins, 2009, p. 5) and the necessity for a Black female-centered analysis in order to counter all other analyses (Hill-Collins, 1997). Essentially, Black feminist thought is about providing physical and intellectual space, and allowing Black women to tell their own stories and in their own way.

Much in the same breathe, CRT investigates the relationship between the law and racial power (Crenshaw, 1996), and situates white-privilege and white-supremacy at the heart of institutional structures/laws which enhance the oppression of people of colour (Crenshaw, 1996) This theory places its emphasis on racial discourse and analysis. Other pioneers of CRT include Derrick Bell (1973), Patricia Williams (1992), Richard Delgado (2012), and Mari Matsuda (1993) respectively, all of whom interrogated the hierarchy of racial oppression in critical legal studies.

Bell (1973), a pioneer civil rights advocate and lawyer, spearheaded many student and social protests at Harvard University in attempts challenge hegemonic discourses around race, 
civil rights and the law. Bell is cited by many scholars (Crenshaw, 1996; Landson-Billing,1998; Solorzana, 1998; West,1993) as the pioneering scholar of the phrase critical race theory in legal studies and education. In Race, Racism and American Law Bell writes about race in American law and society, and argues that white-Americans may never support civil rights because it would deny them of their supremacy. He conceptualizes CRT as an examination of the racial issues within the context of their economic and social and political dimensions from a legal standpoint (Crenshaw, 1996). Bell's (1992) work on CRT was vital in reaching the masses in America Bell's passion for civil rights has had a profound influence on the legacy of CRT, and is evidenced through current scholarship on law, race and gender studies.

Much like Derrick Bell, Patricia Williams (1991) is also a legal scholar and a major contributor to CRT, who has written extensively about the theory and practice of CRT and its place in American law. She argues that traditional civil rights law benefited whites and blacks alike. In the Alchemy of Race and Right Williams uses the tenets of CRT and legal studies to explore the intersection of race, gender and class in America, and critiques liberalism, noting that racism has been normalized in America through the law. Williams also highlights the importance of the storytelling and experiential knowledge, and notes that it is only through such a process that racism can be understood. To avoid confusion with other understandings of storytelling within CRT (discussed later), I note here that her focus on storytelling is specific to the notion of valuing the lived experience from the participant's voice and perspective, rather than imposing understandings based on observation and assumptions.

As a co-founder of the critical race theory school of legal scholarship, Richard Delgado (2012) is also a civil rights scholar who critiques hate speech and racial discrimination in American law. In Critical Race Theory: An Introduction, Delgado provides an in-depth outline 
and analysis of CRT for postmodern legal thought, and challenges traditional legal study pedagogy. Like his predecessors, Delgado also stressed the importance of storytelling in CRT as a form of resistance, and to interrupt the single-narrative of Blacks and Latinos, whereby the uniqueness of specific racialized identities is unearthed and explored through the specific stories of members of those communities, rather than a meta-narrative of the racialized self. Along with his wife Jean Stefancic (2012) Delgado has coauthored numerous books and articles on hate speech and the subordination of minorities in the American legal system.

Lastly, Mari Matsuda (1993) is a leading scholar in CRT and a self-professed activist scholar. She was the first tenured female Asian American law professor in the United States (at UCLA) and has written a number of publications on reparations and affirmative action. Notably, Matsuda's work in Words That Wound: Critical Race Theory, Assaultive Speech, and the First Amendment highlights everyday racism and racist speech. In it she notes the negative and direct harmful effects of racist speech and argues that racist speech has the potential to cause physical and emotional damage on those on the receiving end.

The above discussion reveals a common framework among CRT scholars - that is the majority are students and scholars of critical legal studies/thought and civil rights and examine racial issues from a legal standpoint. For the purpose of this study, I will be focusing on Crenshaw's (1996) conceptualization of CRT. Here, I am particularly interested in her emphasis on inter-sectionality - that is the ways in which race, gender, class, national origin, and sexual orientation serve to further marginalize and discriminate Ghanaian-born women.

As a resistance to white-supremacy patriarchy and in support of race and gender discrimination, Crenshaw notes that women of colour experience overlapping forms of oppression and discrimination, and we cannot, and should not look at them as separate entities in 
any analysis of the judicial system. The Anita Hill case (the Black woman who accused thenSupreme Court Nominee Clarence Thomas of sexual harassment), in which Crenshaw became a ground-breaking advocate and legal representative, centred on the narrative of Hill. I am also interested in CRT's storytelling (albeit not specific to Crenshaw's work) as a way to highlight racial and gender oppression. As noted by CRT scholars, storytelling is an important element in CRT, because it is through hearing first-hand stories and experiences that we can begin to appreciate the truth of racism, sexual, and gender discrimination and oppression (Bell, 1973, Landson-Billing (1998) asserts that storytelling is also an important aspect of CRT because it provides " the necessary context for understanding, feeling, and interpreting" (p. 13) people's lived experiences. Delgaldo (2012), a huge advocate for storytelling in CRT, suggests the use of narratives and voice in (through parables, stories, counter-stories and poetry) is a means by which oppressed individuals can communicate their realities, and interrupt eurocentrism and the notion of the universal subject (white-male), while exposing oppression.

Before proceeding further, I want to highlight an important point about this concept of storytelling. Solorzano and Yosso (2002) contend that storytelling and counter-storytelling in CRT is not only about telling stories or legitimizing the experiences of marginalized people, it is also about challenging dominant discourse and theories (used to explore the experiences of people of colour), and reconstructing knowledge around the experiences and identities of people of colour. Notably, Solorzano and Yosso (2002) note that there are three primary types of counter-stories: "personal stories and narratives; other people's stories and narratives; and composite stories and narratives" (, p. 32) and define the process as counter-storytelling: ...a tool for exposing, analyzing, and challenging the majoritarian stories of racial privilege. Counter-storytelling can shatter complacency, challenge the dominant 
discourse on race, and further the struggle for racial reform. Storytelling and counterstorytelling these experiences [of people of color] can help strengthen traditions of social, political and cultural survival and resistance (p. 32).

As noted above, people understand and interpret their social and material worlds in multiple ways. The practice of oral history and/or story-telling in CRT is particularly important for marginalized and historically oppressed communities because it is about giving meaning to experiences in the context of social relations and also involves "naming one's own reality" (Delgado, 1988, p.33 ). Secondly, as mentioned earlier, story-telling is a counter-narrative which serves as way of giving voice to marginalized peoples, while at the same time interrupting the power of the dominant group to create identity for others (Ladson-Billing \& Tate, 1995). Therefore, any analysis about marginalized people that does not include their narratives and voice is inauthentic and incomplete (Delgado, 1988; Solorzano \& Yosso, 2001; 2002).

The integration of CRT in my own research is not only about examining the state and systems of oppression, it is also about hearing how these young women understand and make sense of their struggles and successes. For instance, I was able to elicit the nuances of their lives through the sharing of their experiences. In one particular example, I could hear the tension and disconnect between one of the participants (Adwoa) and her mother as she relates examples from her childhood. And although the same interview questions could have been asked through a questionnaire format, the face-to-face interview and story-telling process presented elements of tone, non-verbal body language and probing - all of which increased the richness of data. In this way, the process of storytelling in my research study, informed by my theoretical framework, also afforded an opportunity of counter-storytelling that resisted the homogenized narrative of the Black, African, woman experience. 
While black-feminist thought has been criticized for neglecting to acknowledge the experiences of black women outside of the U.S, Hills-Collins says it is about situating the experience of gender and the exploitation of women of colour globally. Black-Feminist thought is also about highlighting the experiences and lived-realities of African-American women. And while such oppression and inequalities are equally experienced by continental women, it would be an injustice to homogenize the two distinct experiences. The take home point here, is that while African-American and continental African women both experience oppression and marginalization, it is important to articulate and highlight how such oppression is experienced differently. And while this study is not central to the tenets of Black feminist thought (because it does not focus on African-American women), it is difficult to have any discussion about gender and race within Canada, without a critical lens and voice of African (descendant) women themselves, which is the fundamental premise of Black feminist perspective and narrative analysis. It is with this understanding that I undertake this theoretical framework in my analysis of the experiences of Ghanaian-born Canadian women.

The final theory used in this inquiry is African Diasporic feminism. African Diasporic feminism places its emphasis on the lives of African-descendent women, and focuses on theorizing the ways in which structural powers aid in the oppression and marginalization of African women, both on the continent and in the diaspora (Wane, 2007), as illustrated in the works of Boyce Davie (1986), Obioma (1998) and Taiwo (2003) to mention a few. Massaquoi (2007) articulates it best:

Black women in Canada are faced with the same dilemma as those living in the modern African Diaspora: of negation and invisibility. We are forever caught in a viscous cycle of searching for an identity and security in a system that negates our race, culture, character and beauty through daily spirit-murdering assaults... [African Diasporic Feminism] is a feminism based on time, geographical placement, displacement, and 
movement. It is a feminism that understands and accounts for the regulating and defining of black women depending on our location.

(Massaquoi, 2007, p.75)

Massaquoi's quote suggests that African Diasporic feminisms in Canada can offer a more nuanced understanding of Diasporic political life. In fact, an African Diasporic politic borrows from transnational studies, as well as Black feminist thought, and is "based on an understanding of African socio-cultural realities, feminist traditions and philosophies and...aims to develop gender-focused frameworks of analysis that can bring out the multiple and varied social locations of African women while maintaining their specific identities and priorities" (Steady, 2005; p. $314)$.

More specifically, many African Diasporic feminists argue that the paradigm resists the notion of studying women only from the perspective of women, for women, by women (Blay, 2008). Instead, African Diasporic feminism creates and encourages holistic studies of Africans, by Africans, for Africans from the experiences and reflections of both men and women. It is not homogenous and patriarchal-focused but rather it focuses on a theoretical model that is able to contain the varied positions (Mekgwe, 2007). In Evelyne Togomoh's Experiencing African Feminisms, she makes a critical case for a new understanding of how feminism operates under a neo-liberal capitalist Africa, and argues that feminism, and African feminism in particular, is a complex discourse, and must involve critical interrogation. Steady (2005) says it best when she writes that an African Diasporic feminism encompasses a "historical perspective, a holistic perspective, multidimensionality, multiple time frames, multiple levels of analysis, multiple identities and realities, relational and dynamic contexts, comparative methods, oral history, life history, and so forth" (p.327). It is important to note that African feminists are less concerned about language and definitions, and more concerned about the usefulness of the framework. And 
although it has been criticized by liberal white feminist, for its lack of concrete definition, methodology and language, Yaba Blay (2008) reminds us that "rather than provide an exhaustive definition, the African-Diasporic feminist framework provides a blueprint for action" (p.68). Said another way, African Diasporic feminism is a resistance and response to having to imitate Western feminism's concern and articulation of the binary use of masculine and feminine.

Like many African feminist scholars (Adichie, 2014; Aidoo, 1992 Blay, 2008; ElaborIdemudia, 2001; Mama, 2011, Obioma, 2005), I argue that the concept of feminism unintentionally reifies a white middle-class elitist lifestyle, which may only be obtained through economic privilege or entry into a global neoliberal market. I also question the romantic desire, capacity, and comfort to create a feminism that is only reflective of white liberal feminism. African feminism need not mimic Europe's/American colonial habits. One must appreciate the effort to re-work popular harmful narratives of Africa in the face of continued misrepresentation. Put another way, the need to define African feminism, is an attempt to mimic whiteness, one that is reflective of Africa's colonial baggage. African Diasporic feminism is developed in villages where the inclusion of women was evident in the social, economic, ritual, and political spheresand not in the academy (Aidoo, 1992). If any theoretical and/or methodological framework is to be adopted in studies about African women, Yaba Blay (2008) argues that "it must be indeed African-centered, functional and practical" (p. 66). For Blay an "African-centered feminist perspective" does not simply imply a narrow focus on women's lives; rather, it allows the researcher to begin a systematic inquiry into where women are differently located. The goal of the African and Black feminist researcher, then, is to not only centralize Black women's voices, but to challenge mainstream conceptualizations of those voices.

It is with all these points in mind that I propose an exploration based on a CRT, Black- 
Feminist perspective and African Diasporic feminism which invites all Black women to tell their stories of life in the Diaspora. It is in the process of telling one's story, as a form of counterstorytelling current narratives (Solorzano \& Yosso, 2001, 2002), that we may begin to challenge the oppressive structures and institutions that shape Diasporic life. 


\section{CHAPTER FOUR: METHODOLOGY}

Being raised as a young woman within a male-dominated society, I believe we have a unique experience of identity formation, both within the Ghanaian community and the larger Canadian society. As a feminist researcher, I have a particular interest in researching the experience of being female in my community. I am interested in how we struggle (or do not struggle) for identity within this context. As such, my work is guided by feminist principles namely subjective truth, unequal power relations, resistance to institutional discrimination along racial, gender, sexual and ethnic lines (Davis, 1981; Dominelli, 2002; Hawkesworth,1989; hooks, 2002; Mohanty, 2003)as articulated through Black feminist thought, and a African Diasporic feminist perspective, which command attention to notions of "voice and the needs of informants and communities involved in explorations" (Okele-Ihejirika \& Spitzer, 2005, p.56). For me, a "feminist perspective" does not simply imply a narrow focus on women's lives; rather, it allows the researcher to begin a systematic inquiry into where women are differently located (Okele-Ihejirika \& Spitzer, 2005).

It is with this in mind, that I ground this project in feminist theoretical frameworks. But I know that the research process is not merely about theory. Rather research looks at the relationship between theory and practice, and makes clear correlations (Creswell, 2007). Therefore, we can assume that there is an inherent link between both theory and practice; they are not exclusive of each other. The feminist paradigms used here help to shape my research questions, concepts, operationalization and specifically, my methodology. Thus, the theories

used in this research (Black feminist thought. CRT and African Diasporic feminism) provide a lens into the social world of Ghanaian-born females, and also shape the operational (methods) tools used to generate such knowledge. 
Consequently, the methodological process within this study speak volumes to my interpretation of social research. Because a critical component of qualitative research in social work is often to develop and identify theoretical concepts and explore an interaction between theory and practice, grounded theory (GT) is frequently the method of choice (Padgett, 2008). However, GT has been critiqued for its centering of the researcher as expert, through decisions based on theoretical sampling and theoretical saturation through the iterative recruitment, data collection and data analysis process (Thomas \& James, 2006; Wuest \& Merritt-Gray, 2001). More recent development of GT methodology, through Constructivist Grounded Theory (Charmaz, 2012) seems more aligned with social work research because there is a common element of co-creating knowledge between researcher and respondents, while at the same time focusing on the application of theory to real-world experiences. GT initially seemed an appropriate methodology as it could help to fill the gaps by first looking at the existing literature about Ghanaian-born women, and then intentionally selecting these participants whose experiences were largely missing from current scholarship. I also assumed the abductive nature of GT could be instrumental in filling the gaps because it can incorporate and validate the narratives of the participants, while at the same time developing theoretical understandings that could explain the social processes that informed these women's understandings of their experiences, whether that be "social psychological or social structural” (Crooks, 2001, p. 12). However, as discussed below, my initial plan to use grounded theory did not fit with my overall intentions as I more fully developed my methodology.

In order to obtain detailed firsthand accounts of the experiences of youth within a contemporary context, I intended to use eight personal interviews using an interview guide with open-ended questions. I wanted to know what happens and how Ghanaian females interact 
within their hybrid identities. I started by asking participants demographic questions to ensure that the participants closely represents the intended population/groups. The types of questions included age, sex, marital status, income, and employment status. I then began with openquestions, with the assumption that I knew very little about my participants. I also relied on the existing scholarship to help in identifying the existing gaps in knowledge which further informed my interview guide. Accordingly, I wanted to learn how participants made sense of their migration experience and their multiple identities within the Canadian landscape. For this study, I specifically asked two research questions that were open and focused on participants' social meanings: Firstly, how do young Ghanaian-born women understand what it means to be both Ghanaian and Canadian? Secondly, in what ways do gender, race and culture inform or not inform their understandings of what it means to be Ghanaian and Canadian? The purpose of these questions is to investigate how young Ghanaian-born women traverse through cultural expectations of Ghana and Canada.

In developing these research questions, I had hoped to develop a theoretical understanding of the experience of young Ghanaian women, by seeking a mapping of the processes that specified their experiences in contrast to the dominant scholarship of a singlenarrative of the Black woman experience. I was curious to understand how young Ghanaian women embodied and resisted this single-narrative, and conceptually mapping the processes that informed both that embodiment and resistance. Grounded theory (GT)seemed a good fit, as it focuses on the interaction between the people and their social environment (Oktay, 2012) to create theories from real-life experiences. Secondly, grounded theory methodology is rooted in the identification of theory, concepts and explanations of phenomenology which is grounded in data, and is examined through both an inductive (theory generation) and deductive (theory 
testing) logic (Oktay, 2012). Third, as both a response to social work practice and as an educational and research model, Glaser and Strauss contend that grounded theory involves the development of "middle-range" theory (because it falls between the applications of real-world experiences) and "grand-theory" models, and is an "abductive process-where theory is derived inductively from the data, and confirmed deductively by exploring additional data" (Oktay 2012, p.149). In essence, Glasser and Strauss stress that the development of theory based on empirical observation makes grounded theory important to social work practice, and research. This is particularly important because social workers require non-abstract theories on the frontlines, and grounded theory has great potential because it is a "middle-range theory" (Oktay, 2012) that is not too abstract and can be applied to real world problems. However, as I moved through the process of engaging with my research questions and preparing for data collection, it became clear that my methodology was more of a narrative approach.

To begin with, upon reflection it is clear that my research questions themselves are about opening up the unique stories of young Ghanaian women and the meaning they make of themselves, through their understandings of their identity as both Ghanaian and Canadian, and the influence of gender, race and culture. In this way, I am seeking narratives about their lives but I have not particularly focused on specific processes and social relationships that these women experienced. Unike GT, all of my interviews were completed within the same time-frame prior to continuing to the data analysis. As such, my methodology began to shift away from some of the core principles of grounded theory. Given this shift, I felt it necessary to consider other methodologies to inform my inquiry. In particular, I was drawn to narrative methodologies, given the focus on storytelling in the interviews I conducted, as well as my interest in the meaning these women attributed to their experiences. 
In examining my interview questions it also became clearer that I was drawing from narrative methodology (Mishler, 1995; Riessman, 1994), with open-ended questions that focused on particular aspects of young Ghanaian women's lives without being directive or limited to specific elements of their experiences. I decided to use thematic narrative analysis because participants' stories could be used to develop an understanding grounded in their experience (Riessman, 1993). Secondly, I reviewed all the interviews at once, which helped to reveal significant themes among and between participants. This consistency of themes across and within participants is what Patton (2002) refers to as "substantive significance" (p. 234I found myself employing the narrative analysis process in using across-case thematic analysis of the participant interviews at the same time, and in doing so, of excavating and unearthing personal experience, in which storytellers (participants) interpret the past, rather than reproduce it as it was. Moreover, participants' ideas, themes and connections were noted and coded to show the frequency and the significant themes. (I explore the process of coding in detail later in the next chapter). Third, I chose thematic narrative analysis because the themes supported the data and generated a deeper view of life, by the process of meaning-making of participants' experiences (Riessman, 1993). In her work, Riessman (1993) writes that "locating narratives of personal experience for analysis is not difficult. They are ubiquitous in everyday life" (p. 2). I found that the respondents in this study organized their thoughts around stories, specifically narratives of their past and present experiences. These factors logically led me to adopt the narrative analysis methodological process.

\section{Narrative Analysis}

Narrative analysis methodology is rooted in human interaction in relationships and lived experience (Riessman, 2005). With its genesis in the 1960s, narrative analysis (NA) dominated 
multiple disciplines in the social sciences including philosophy, history, anthropology and sociology. But much debate has been developed about the definition of narrative analysis, with no clear operationalization (Riessman, 2008). Referring back to the genesis of NA, Riessman and Quinney (1993), Mishler (1995), Labov (1997), and more recently Clandinin (2006) and Riessman (2008) have influenced the discourse and scholarship on narrative analysis as a form of research endeavour. Notably, Riessman (2008) has written extensively about NA and notes that narrative inquiry reveals "realist, postmodern and constructionist elements" (p. 5), which involves in-depth recorded interviews of participants. NA also responds to and interrupts dominant, often negative discourses about marginalized people, and helps them to make sense of their experiences through storytelling (Riessman, 2008) - all the while, reclaiming their identities. In my quest to understand the identities of young Ghanaian-born females, NA proves to be a useful tool. Again, in narrative inquiry, researchers collect many stories and inductively create conceptual groupings from the data.

According to Riessman (1993), "personal experience as narrated by the teller, is of utmost importance in qualitative research" (p.3). For narrative analysts, interest lies in the who and what (content of speech) of storytelling. Notably, researchers interpret what is said by focusing on the meaning. Essentially, language is "viewed as a resource, not a topic of investigation" (Riessman, 1993, p. 3). Within this approach the goal of the research is to rely mainly on the participants' response and accounts (situated historically and politically) of the phenomena being researched (Riessman, 1993).

Although most narrative inquiries begin with asking participants to tell their stories, either in one-to-one situations or in groups, hooks (1997) explains that people's lived and told stories are not linear - they do not necessarily "move from point A to point B." Contemporary 
narrative analysts such as Clandinin (2000) assert that it is important that the voice of the inquirer not write over the voices of participants in the final research texts by using an overly dominant researcher tone/language. To avoid this, one must adopt inserting parts of the interview to give voice to participants - a method I have adopted throughout my analysis You will note in Chapter Five (Thematic Analysis) that the themes are divided into five categories: extended family, gender politics, identity, transnationalism and religion, with each consisting of direct quotations from the in-depth interviews. These coded labels come from the voices of the young women through storytelling, and the meaning they ascribe to their personal experiences.

Despite its convenience in data collection, critiques of narrative inquiry suggest that research settings and relationships constrain what can be narrated, and shape the way a particular story develops (Clandinin \& Huber, 2007). For instance, my recruitment and interview process was complicated by my close proximity to the Ghanaian community within Toronto, specifically the church community. Therefore, I was aware and careful of my role as a leader and working professional within the community, and the implication this had on participants' willingness and comfort in telling me personal and intimate accounts of their lives. This was addressed through assuring participants of my obligation to confidentiality and privacy through the Research Ethics Board at my institution. Participants were also informed that they did not have to answer uncomfortable questions. During one of the interviews, I immediately ceased the recording when the participant became emotional and consulted with her (albeit off the record) before proceeding with the interview. She assured me that she wanted to continue rather than skip the question. Another limitation in narrative analysis is that there is a real danger of over-personalising the personal narrative, in which the researcher pretends to offer an authentic voice. This can be problematic particularly because it renders the participant powerless and incapable of 
consciousness and advocacy. My unique position, as a member of the Ghanaian community and a continental-African female, means that I am familiar with some of the experiences of these participants. This could lead to assumptions and preconceived notions of what it means to be a Ghanaian-born female. The danger in this is it has the potential to influence the analysis and findings process of my research. In order to limit researcher bias, I allowed the women to tell their stories in their own way, with little interruption and by only asking for clarification when I was ambiguous about something.

Despite its limitations, I used narrative for two key reasons. First, I wanted to focus on how these women talk about and evaluate their experiences and current situation. This is particularly important because I was also interested in if/how these young women perceive and understand their lives different from the broader Canadian population, and also in relation to other Black communities/identities. Secondly, the use of narrative analysis also served as a tool to connect similar details of participants' experience to broader social contexts, which also corroborates with my theoretical frameworks of doing indigenous feminist research that challenge gender, racial and power relations.

\section{Sampling}

Sampling in qualitative research can be characterised by multiple stages. As a result, different sampling techniques can be used at different stages of the process (Creswell, 2007). As noted by Padgett (2008), sampling should be driven by the research question and goals. Rubin and Babbie (2008) also note that sampling in qualitative research is more often purposive. Such sampling techniques include "maximum variation sampling, homogeneous sampling, typical case sampling, extreme case sampling, critical case, total population sampling and expert sampling” as outlined by Patton (2002, p. 232), with each having its own goals and objectives. 
Through the process of carefully selecting participants based on shared traits (gender, race, ethnicity, and background), this study adopted a homogeneous sampling technique. Specifically, my aim was to adopt homogeneous sampling seeking high school-aged and post-secondary-aged participants of young Ghana-born women, who have resided within the Greater Toronto Area for a minimum of five years. This was to ensure that participants had some level of engagement and exposure to various aspects of life in Canada (employment, education, social, political) as the purpose here is to understand experiences and identity formation within the context of gender, culture and race across life experiences. Priority was also given to young Ghanaian-born women. The rationale is that although similar, there are vast differences between the experiences of Ghanaian-born young women and their Canadian counterparts, which also requires further analysis. However, for the purpose of this research, I focused on Ghanaian-born young women. Priority was also given to those individuals who attended elementary/middle/high school, with at least some post-secondary education in Canada to help capture different stages of identity formation. The aim here was to draw a wide range of participants, and although my goal is not to make generalizations from the findings, Rubin and Babbie (2008) note that sampling should encompass a wide range of participants in order to cover range of perspective of participants including some who had post-secondary education, rather than focusing specifically on achievement of completing a specific level of education. This is also to highlight the complexities some people experience when migrating as a child/teen as opposed to the difficulties experienced as an adult. Therefore, it is important to understand and reflect on ways in which migration affects children differently. Rumbuat (1991) notes children process acculturation and education significantly different and begin their adaptation processes in very different social settings. For this reason, it is particularly important to examine and understand 
these participants in relation to their point of entry into Canada. This is also important because it provides and considers multiple possible determinants of results.

With regard to sample size, the initial goal was to interview eight participants. However due to the time-constraints and the number of participants who contacted me, I completed a total of three interviews. Each participant was interviewed a total of one hour to an hour and half. Although the sample size is smaller than the anticipated number, I was more interested in depth and intense data rather than the number of interviews. This speaks to the flexibility of qualitative research in maximizing quality over quantity, and in stressing the importance of "saturation with information/data" (Padgett, 2008, p. 103).

\section{Recruitment}

For the in-depth interview, participants were recruited through social gatherings, Ghanaian churches, social organizations and educational institutions (Ryerson University and Seneca College) by handing out flyers and putting posters up on bulletin boards. Along with this, the recruitment flyer (Appendix A) was used as an ad in the community newspaper for one circulation (one month). The same flyer (Appendix A) was used as a poster at the campuses of Centennial College, Humber College, Seneca College, Ryerson University, and York University, as well as at the community churches.

My aim was to get the word out about the research and make contact with enough potential participants. However, my recruitment flyers were not particularly successful in attracting potential participants to my study. In the end, it was through social events and contacts that I was able to reach and familiarize myself with potential 1.5 generation women, by way of snowball sampling or chain-referral sampling- a non-probability sampling technique used to reach potential participants where participants are recruited by acquaintances who themselves 
participated in the research, because participants are hard to locate (Norris, Harrington, Grossman, Hemed \& Hindin, 2015).. Rather than being asked to identify their peers to me, participants informed their peers about the study and allowed them to decide whether they wanted to participate. As a 1.5 generation Ghanaian-Canadian woman, I see the necessity of privileging these voices, while recognizing the ways in which these voices may also speak with other marginalized groups. For this study, the 1.5 generation is characterized by those who were ten-years of age or below when they immigrated to Canada. Rumbuat (1991) notes that the age of ten was chosen to reflect individuals who received some primary education in a host country, while at the same time sharing the parallel worldviews with the second generation (children over the age of ten). This is particularly important because by the age of ten-years-old children have acquired adequate language and cultural exposure in the home country, and have been influenced by family and close relatives before migration.

Along with this, I also consulted with community leaders (mostly through social organizations) who referred me to potential participants. It is important to note that these potential participants did not materialize because the leaders informed me that most of the 1.5 rarely attend the monthly meetings, unless there is a special event. The same issue arose with recruitment in the churches, where potential participants were either too busy or had fluctuating attendance. Once I made contact with potential participants, scheduling also proved to be problematic, as most of these individuals were either fulltime students, or employed full/parttime, or with other personal obligations. In all honestly, it was difficult to recruit participants, because of the length of time between my initial recruitment (which began in winter 2014) and the actual interview (the first interview was in summer of 2015). In the end, I included first generation because it was hard to recruit 1.5ers due to time constraints and lack of access. As 
discussed earlier in Chapter One, the term first-generation is used to describe the children of immigrants who have been raised in the native country (Manuh, 2005; Opoku-Dapaah, 2006; Owusu, 2006; Wong, 2000). The use of first-generation has also been used to describe the first group of immigrants to migrate and begin building their lives in a host country (Agyekum, 2012; Donkor, 2000; Firang, 2011; Kitson, 2003; Kobayashi, 2008; Yesufu, 2005). This definition infers that the immigrant parents of Canadian-raised Ghanaian children would be considered first-generation Ghanaian-Canadians. This definition is also based on the premise that immigrant parents are the first to obtain formal Canadian citizenship status, granting them legal permission to be identified as Canadian. But Mensah (2002) and Abdi (2005) note that many immigrant parents are less likely to identify as Canadian outside of official government matters due to the experiences of racism and discrimination in the host country. Moreover, these scholars note that the resistance to solely identify as Canadian is also a result of the maintenance of transnational ties-through financial, spiritual, emotional and familial connections with their home country. Canadian-raised children are more likely than their parents to identify as Canadian because their life experiences have been shaped by their physical presence and integration in Canada. With this in mind, I will rely on the use of "first-generation" to refer to the children of Ghanaian immigrants in Canada.

With all that said, it was also easier to access first generation because the Ghanaian population has experienced a dramatic increase in youth between the ages of 12-26 years of age, as parents are sponsoring their children in large numbers due to accessible immigration policies (Manuh, 2005). As a result of such trends, Ghanaian youth (specifically those who migrate in their adolescent years) are becoming an ever increasing presence in the community. As a result, three participants were interviewed, two of whom were $1.5 \mathrm{ers}$ and were informed about the study 
through personal contacts that I made at social events. One of the participants was particularly interested in the research topic, because she "was interested in applying for a Masters of social work." Another participant was a first gener and was recruited through a social organization. She notes that she saw the flyer of the study during one of the monthly meetings. All three participants were informed of the voluntary nature of the interviews and the ability to withdraw from the study at any time. Prior to meeting with each individual, I emailed and introduced the research and explained its purpose, risks, benefits and confidentiality and what their participation will look like, along with the consent form (please refer to Appendix B and E).The email also provided my contact information, and details about the incentive (\$10 Tim Hortons gift certificate).

\section{Participants}

My recruitment was specific to young Ghana-born women between the ages of 18-30 years, because this demographic was explicit to my research topic. Although there is the necessity for a study on Ghanaian-youth (both male and female), the goal of this research is to investigate and have a greater understanding of the patterns some Ghanaian-born Canadian young women experience in their attempts to integrate into Canadian society. Though the participants in this study experience migration differently -based on family structure, exposure to gender politics, religion, and socioeconomic status - all of this contribute to their own meaning of identity within the Canadian landscape.

The age-range (18-30years) was to ensure that participants are legally able to take part in the study (without the requirement of parental consent). The range also ensured that participants have an understanding of the concepts/scope of the expectations and interview questions. As mentioned earlier, this age range also was necessary so that participants have exposure to 
Canadian life and education. Participants were also required to have resided within the Greater Toronto Area for a minimum of 5 years. This was to ensure that participants have had some level of engagement and exposure to various aspects of life in Canada (employment, education, social, political) as the purpose here is to understand experiences and identity formation within the context of gender, culture and race. Moreover, participants were required to use their real names when first contacting the researcher, and also to sign the consent form. Following this, pseudonyms were used, with a separate list of the real names coded with the pseudonyms that only the researcher had access to.

As a feminist researcher I am particularly aware of the stark similarities between myself and the research participants, and took measures to safeguard bias. I will return to my role as both an insider-and-outsider later in the discussion, but for now, I will be focusing on the method of data collection.

\section{In-depth Interviews}

According to Kvale (2007) in-depth interviewing is a process within qualitative research that requires pre-arranged questions by the researcher, with a small sample group, to investigate their perspective on a paradigm, phenomenon and situation. In-depth interviewing is a chance for "the researcher to become the leaner" (Padgett, 2008, p.100). For instance, in order to explore the experiences of immigrants and employment, Boadi Agyekum (2012) and Wong (2000) conducted personal in-depth interviews of respondents to understand their peculiar situations in the labour market. Boyce and Neale (2006) notes that in-depth interviews should be used to elicit and distinguish individual opinions about an event or situation, or in circumstances were respondents may not be comfortable talking in group settings such as focus groups. Interviews, according to Kvale (2007), also focus on language and meaning and address important issues in 
participants' social world. It is with this in mind that I endeavoured to use in-depth interviews for data collection. My use of in-depth interviews is threefold. First, the interview guide questions were generated with the research question in mind. This means I was seeking participant responses that either directly or indirectly address the phenomenon being studied -often uninterrupted by me. Secondly, in-depth interviews elicit an open-ended approach to questioning, which enables participants to volunteer (or not) information (Padgett, 2008), with the influence of probing. Finally, though the questions are prearranged and require close attention to detail, in-depth interviews makes room for improvisation, but simultaneously allows the participant to decide what information to share.

The interviews in this study were audio recorded and were approximately an hour, and consisted of an interview guide with open-ended questions. These questions served as a guide, and were not intended to help focus the interview; rather, they were designed to help to stream the interviews for specific wording and responses. The questions centred on family dynamics, gender roles and cultural expectations. The participants did not have access to the interview questions ahead of time nor did I give them a copy of the questions during the interview. The purpose here was to explore the issues and not interrogate the participants. I used probing and follow-up questions if/when necessary, without being too intrusive.

\section{Analysis}

This section discusses the ways in which the data was analyzed using thematic narrative analysis to identify themes that emerged from comparing the common characteristics from the interviews. The focus here is to analyze what shapes the immigration, adaptation, and civic participation of Ghanaian-born women, teasing out the empirical relationships between the hybrid-identities of these participants and the meaning they make of these experiences. 
I began by transcribing (line-by-line) using NVivo software and then doing a readthrough of the transcripts, using "inter-and-intra-comparison of the interviewee responses" (Floersch et al., 2010, p. 157) to identify the patterns. Inter-and-intra comparison, according to Floersch et al., refers to the process of analyzing inside and across multiple cases, and involves accumulating knowledge about data, comparing and contrasting such data, and in doing so, producing new knowledge. For example, participants were asked: what is it like growing up female in a Ghanaian household? This yielded a common response from the participants about gender-politics and gender-specific role expectations from their family and community members. I then used the iterative process of coding, in which, meaning is assigned to interview data (phrases, sentences and words) to identify and ensure meaningful labelling (DeCuir-Gunby, Marshall \& McColloch, 2011). I then used line-by-line coding to develop key themes: extended family, gender politics, identity, transnationalism and religion, and used examples of each component to confirm my analytic decisions when naming codes.

The iterative process of coding allowed me to begin examining whether the data supports or contradicts my research question and theory. I wanted the raw data to guide the research. It was important that the codes and data were guided by principle theories of Black feminist thought, CRT and African Diasporic feminism, rather than pre-conceiving constructs of these women's experiences.

In using narrative analysis to look at the stories, the aim was to reconstruct the interview data to explore identity, gender, citizenship and the migration process. Secondly, by reconstructing the narratives through the use of quotations, I was interested to know how the participants responded to the challenges and opportunities associated with both of their national identities. From the participants' perspective, being Ghanaian and Canadian is inter-sected with 
their everyday experiences - and is not mutually exclusive. Although their narratives were not linear -moving from point A to B - the participants made sense of their life before migration, life in the diaspora, and a prospective life as a Ghanaian-Canadian young woman. It is important to state that the interview itself was not necessarily designed to create a linear story (from A to B). And as noted earlier in the chapter, NA does not have a linear pattern, and in this study, the stories were not fully structured or orderly.

\section{Positionality}

I undertake this project with some critical knowledge of the importance of community. As a young Ghanaian women, who migrated at the age of 7, I am the product of an Ashanti father and a Fante mother. As a feminist researcher, I am invested in research methodologies that stress collaboration, anti-oppression and shared experiences between the researcher and participants. It is through this understanding that I also see the necessity in engaging in narrative research that implores insider knowledge by way of informal interactions. The concept of insider-outsider in qualitative research refers to a researcher's position in relation to the participants and/or community being studied (Humphrey, 2007). Research with communities is first and foremost about establishing relationships - "with no beginning and no end" (Potts \& Brown, 2005, p.263). It is also about unpacking our (researcher's) preconceived notions of truth and "working the hyphen to probe and negotiate with participants about whose story is being told, and how it is being told" (Fine, 1994, p. 72). To complicate things further, Hill-Collins (1986) highlights an another position "outsider-within" and contends that marginalized bodies (black women academics in particular) work and operate within white-supremacist organizations/institutions daily, but are controlled by the insider group (whites/Europeans) and not given the rights and privileges. She challenges qualitative researchers and academics alike, 
to activate the hyphen - the middle space - as both an insider and outsider in order to resist and awaken the tendency speak of and for others.

Additionally, the term insider refers to a "situation where the researcher is a part of the topic being investigated... and usually have an ongoing connection with the research participants," while outsider researchers consists of those who do not have a shared identity with the participants (Sherry, 2006; p. 433). Drawing on feminist understandings of the insideroutsider discourse, I knowledge the power dynamics between researcher and participants, and the shift in standpoints throughout the research process. Many feminist researchers contend that researchers should always take caution and attempt to equalize power relations through careful attention to boundaries and ethics (Fine 1994; Fitzgerald, 2004; Humphrey, 2007; Langhout, 2006). Here, I argue that a researcher's position as an insider or outsider impact the research process. For one, no one has an "unadulterated outsider-within position" (Landson-Billings 2005, p. 6); this means, people occupy multiple positions/statuses simultaneously - as both insider and outsider. Secondly, individuals have a relatively privileged position in one or more social hierarchies (Collins, 1990) and may be oppressed in one instance, and oppressors in other situations (Mullaly, 2002).

Thus, my position as an insider-outsider has several implications for my research. My experience as a Ghanaian-born woman researcher whose work centers on African women in the Diaspora, which I situate within Black feminist praxis, certainly shaped my access to the participants and the data interpretation. Having already had access to the community as an insider allowed me to have certain knowledge of cultural practices that I would otherwise not have as an outsider. Having had previous contact with the respondents (through social events/gatherings), I believe provided some comfort and familiarity for both parties. I believe 
participants were also comfortable in sharing their experiences because of my status as a young Ghanaian, who is well-known in the community as an educator and activist. My location as a university student also prompted the participants' trust and confidence in sharing their narratives, as many Ghanaians have a high level of trust and respect for signifiers of authority and higher learning. Some of the participants were especially comfortable with me because they were familiar with my activist work in the community and with youth and families, which I believe empowered participants to further express themselves. For example, one of the participants indicated that her father was a polygamous, and although this is a traditionally common practice in Ghana, it is no longer accepted for moral and religious purposes. However, this participant was comfortable in disclosing this information about her family history. My status as an insider allowed me access to stories that might not otherwise be shared (due to a potential lack of trust with an outsider) and then to interpret the narratives of the 1.5 and first generation in a way that respected the nuances community norms and understandings.

Yet, my social location and status as a Ghanaian also meant that participants were somewhat uncomfortable in divulging particular information about their family. Also, my position as a graduate student meant that there was a power imbalance between myself and the participants. I was intentional in my use of language (non-academic) to decrease the power relations through the interviews. I allowed the participants to lead the dialogue with little interruptions, except for probing and clarification purposes. I believe my positionality as an insider was more beneficial and enabled me to carry through with the narrative process with members of my community in a more egalitarian process. 


\section{Conclusion}

Research is an everyday activity (Creswell, 2007), but over time social research, in particular has been institutionalized and has been allocated to academia and professional settings (where workers are considered experts). However, everyday human interaction suggests some level of doing research. But in saying so, there are ways of engaging in social research, and there are many concepts/models/theories that a researcher must consider and interrogate. Ultimately, all of this is guided by the research topic, research question and methodology (how the research is conducted). The above discussion illustrates how NA was used to collect and analyze the data. In the next chapter, this data will be analyzed and examined based on the theoretical underpinnings of the research questions. 


\section{CHAPTER FIVE: THEMATIC ANALYSIS}

This project is about the importance of African women's life, and is informed and inspired by own personal narrative as a second-generation Ghanaian-born woman living in Canada. The following conversations reflect how Ghanaian-born young women navigate the Greater Toronto Area in terms of identity, language, family and belonging. My aim here is to investigate the difficulties some may experience in their attempts to integrate into Canadian society. As mentioned in Chapter Three, this project is guided by Black feminist thought, CRT and African Diasproic feminism framework, with the aim of critically examining and reflecting on the very personal implications of transnationalism, and in particular how border-crossing affects the identities of Ghanaian-born women in migration. I want to understand the circumstances, the life choices, the struggles, the successes, and an overall holistic appreciation for their journey. The following is a thematic analysis of the individual interviews, in which three Ghanaian-born young women provide their personal, raw and unapologetic accounts of their journey. The identifiable themes are: extended family, gender politics, identity, transnationalism, religion, isolation, and structural barriers. Before discussing these themes, I first provide a detailed description of the participants and their interviews, to situate the themes.

\section{Interview/Participants}

The interviews happened over the course of two months within the Brampton area. With the initial aim of interviewing eight women, I was able to complete three interviews. This was a result of inaccessibility to young Ghanaian-born women, as discussed in the previous chapter. For confidentiality purposes, participants have been assigned pseudonyms to protect their identity and privacy. It is important to note that all of the women had completed post-secondary education, or were in the process of completion. Akosua is a healthcare worker, and has 
completed a certificate program in Health Management. Akua has an undergraduate Degree in Women's Studies. Adwoa is currently completing her Diploma at a local College. All of the women were born in Ghana, and migrated to Canada in the early 1990's, and have spent the majority of their lives in the suburbs of Brampton, north west of Toronto, Ontario. Of the three participants, two went to a predominately white school, where they were the only or one of few Ghanaian students. The participants in this study were raised in predominantly white and South Asian neighbourhoods. They grew up at a time when the face of Brampton looked significantly different than the ethnically diverse city that is presently Brampton. The immigrant population in Brampton went from 79,060 in 1991 to 263,670 in 2011, a dramatic increase of $233.51 \%$ (Statistics Canada, 2011 Census). Brampton's unique immigrant composition plays a vital role in the development of the community through easy access to cultural spaces, resources and investments. In a recent study by Boadi Agyekum (2012), she notes that visible minorities accounted for $57.03 \%$ (246,145 persons) of Brampton's total population. This is undoubtedly a reflection of the increase and influence in the immigrant population.

As for this study, the initial aim was to interview young women who were residents of Toronto, however, the end result was three participants from Brampton, as discussed in previous chapter. Toronto was selected not only because it is home to a sizeable number of Ghanaians, but also because it is where I have the necessary contacts with individuals and community organizations to facilitate data collection. It is important to note here that although most cultural, religious and social activities occur at the northern part of Toronto (North York), I found that a large portion of the Ghanaian population resided in the Brampton area. For example, it is quite common to find an individual who lives in Brampton, but travels to Toronto (North York) for cultural and social gatherings. Although participants were recruited through schools, community 
newspaper, churches, and social events (all in Toronto), the three participants happen to live in the Brampton area. The Ghanaian community in southern Ontario has seen a recent trend in migration to suburbs such as Brampton, Mississauga and London (which is located north-west of Toronto). Many Ghanaians are beginning to make long-term investments by purchasing homes in the suburbs -a different trend from that experienced by earlier Ghanaian migrants, who often resided in lower-income housing, mainly in the Jane-Finch neighbourhood of Toronto (Firang, 2011; Owusu, 1999). There remains a high proportion of the population concentrated in the JaneFinch area (Boadi Agyekum, 2012; Firang 2011).

The narratives shared by participants are from a small homogeneous sample that allows us to explore some central issues raised by young Ghanaian-born women in Brampton. The participants were asked a series of open-ended questions about life in Ghana and their migration experiences in Canada. The following is an attempt to categorize the interview into major themes, and most significant responses about Ghanaian-Canadian life as understood by the young women. Again, I have used pseudonyms to protect participants' identity, and used particular excerpts from the personal interviews. My analysis of the interviews is informed by my social location as a graduate-student, sometimes community advocate, sometimes community-leader, Ghanaian-born woman. It is also important to state here, that such location, along with my other identities (Canadian-educated, half-Ashanti, half Fante woman), lends itself to power and privilege within my analysis.

There is a common narrative within the Ghana-Canadian community about Ghanaianborn children - "born-again" is the popular term often used to describe those who migrated to Canada in their childhood, pre-teen, and teenage years. The narrative goes something like this children and/or preteens who were born in Ghana and migrated to Canada in the late 1980's to 
present, have to learn to reframe and make accommodations to their sense of self. They also have to assimilate to the Canadian way of life, and have to do so in the form of a resurrection. And while the term may be reflective of their migratory experience, many Ghanaian-born youth suggest that it has negative connation, and is a reminder that they, in fact, "do not belong" as noted by one of the participants. Ghanaian-born children have a complex and dual responsibility of being Canadian - but not too Canadian -and are often reminded of the expectation to "act right." As one participant eloquently stated: "I have more responsibilities than my Canadian-born sisters, because I'm just expected to know better because I was born in Ghana." For this demographic, there is the responsibility of a dual identity, a hybrid identity that is at constant negotiation between two worlds, two cultures colliding. I now shift to exploring the key themes that emerged in my analysis.

\section{Extended Family}

The first major subject that I addressed in the interview was about childhood experiences; having been born in Ghana, most of the participants' narrative was central to being born in small cities, and raised by lone-mothers and/or extended family. I say lone" because the participants spoke about being raised by their married mothers, and often their Grandmothers. The absence of fathers in their childhood was often attributed to migration. I will get to this later. But, when asked about her childhood Akosua had this to say:

Akosua: I do remember a little bit, just like faded memories, I guess, I was a toddler. I have a few memories from when I use to stay with my grandmother, umm in [City A]. Umm, I have a few memories from her, and a scar, (laugh) that reminds me of how bad of a kid I was. Umm, but when it comes--and then I remember when we were Accra, we lived in [City B] for -- I know I'd say...I'd give you a time-frame, but it's probably fuzzy. Umm, but we did live in Accra, while my mom, I guess my mom was getting the paperwork and stuff together for us to come Abroad. But I didn't realize it at the time, I only like, based on memories, I piece all that together, and later on in life. Umm, so I, I know 1 lived in [City A] which was like more rural. Umm and then I moved to the city and then moved here. Umm, when we moved here, we moved to Brampton Ontario. 
Umm, first place that we lived was with my Grandmother, my dad's my, dad's motherstepmother.

In fact, all three participants indicated they were raised by their Grandmothers and/or by extended family. Akosua and Akua were raised by their mother and Grandmother, while Adwoa was raised by her mother and uncle. But along with being raised by extended family and Grandmothers, participants also identified the absence of a father in the early stages of childhood. When asked about their fathers, both Adwoa and Akosua indicated that they met their fathers for the first time upon migrating to Canada. Both had this to say:

Adwoa: well, like I said, I came here when I was five and a half years old, so up till then, I spent the majority of my time in a small village called [City C], on the west of Ghana. Um, I don't remember much about the atmosphere -I know who I was staying with, I know I was with my mom, because my dad was here in Canada. Umm, I lived with my, my mother like I said, and my father's oldest brother, and he was like our second father at the time. I was also surrounded by my mother's sisters and most of her family. Umm, I don't remember much about my father's family. But like I said, the majority of my time was spent with my mother's side of the family... and in a small village, we lived in a small house and I stayed with my mom, my younger brother and my older brother at the time.

Akosua: umm, when I was -before the age of five, I hadn't met my dad, and that wasn't because my parents weren't together or anything like that, you know, it was just the whole immigration thing. One parent would come up, and then they'll try and get themselves settled, and then they'll bring their wife and children. Umm, so, I didn't really know my dad until like --I kinda met him October ${ }^{\text {st }}$, '91. Big date. Umm (laugh). But I grew up with my grandmother, and I actually met my great-grandmother, I figure we were in diapers at the same time, so it was pretty cool (laugh).

I think Akosua sums it best in the above quote. The Ghanaian migration experience is

often experienced first by men, who leave their families (in their home country) in search of a better life abroad.

\section{Gender politics}

As part of the interview, I asked a series of questions in order to examine and to better understand the discourse of gender politics and expectations within Ghanaian households. The initial questions were: Tell me about your experiences growing up as a female in a Ghanaian 
household? Were there any cultural expectations of you as a Ghanaian female/woman? If so, what were they? What do you think is the biggest lesson you've learned from the women in your family about being a woman? The personal interviews revealed several significant themes. First and foremost, each participant spoke poignantly about knowing their role and responsibilities, even from a very young age. They spoke about the expectation and accountability they felt even as children, to perform cultural and gender roles. Adwoa articulates it best:

Adwoa: It was...uh to know how to cook, to know how to take care of a household, um...to know how to... uhhh...cater for my father, basically because he's the man of the house, and he's the head of the house. So that's a really big thing. And...Umm...to even at a very young age something that was always emphasized is you need to be ready for marriage, you need to be ready for marriage. It's very serious (laugh).

When asked about her experiences growing up female in a Ghanaian household, Akosua conceptualized it as a constant struggle:

Akosua :( Laugh). Umm, I think my middle-name was House-girl. Laugh, umm being that I was a female, and as well as the fact that I was an only-child, I feel like I had it pretty rough. Umm, being a female means so many things in the Ghanaian household. One, you're expected to know how to cook, and clean, and you know, there's a level of servitude that I feel is just ridiculous. Umm, like you're expected to you know, get up on in the morning on your weekends--maybe in my household, but I was expected to get up on the weekends and clean the house. You know, umm, you know, I would like, you...I don't know for me, I felt as if, even before I knew what sex was, I felt like it was, it was the demon-thing. You don't do that. You don't, you don't have sex. You don't touch boys, you don't talk to boys. It was really weird. I see that they were tryin'a protect me, but at the same time, it was done in, a such a freighting way, that it was just kind of like "ugh!" Being a like, being Ghanaian, being a woman in a household, or a girl in a Ghanaian household, it's, it's hard, cause for me, my relationship with my Dad, was rough. And my relationship with my Mom was rough. And I didn't really understand why? Until I mean I grew up and talked to other Ghanaian women (laugh). We realized that you know, Ghanaian parents are weird as it is. Umm-

Each participant highlighted ways in which their very young bodies/minds were expected to perform gender-roles, to execute gender/womanhood. At one point in the conversation, one of the participants articulates her disdain for assigned gender roles, and her struggle to reconcile with her current role as a wife. For her, it is a constant struggle which, in the past, led to a strain 
in her relationship with her parents. She notes that she continues to struggle with this with her husband because she does not know how to be "submissive." Although they knew their roles, each participant also had ways in which they resisted and learned to pushed-back. They note that they have learned to develop their own value system, while still learning to appreciate their Ghanaian cultural and gender role expectations.

Interestingly, when asked about the biggest lesson they learned from the women in their family about being a woman? , each participant spoke highly of their grandmothers and mothers, and highlighted resiliency, strength and courage as important life-lessons. They spoke about the respect they had for their mothers, while at the same time highlighting the problematic nature of the need to appear strong. One participant noted the unhealthy way in which Ghanaian women (mothers) are committed to maintaining and holding up a strong exterior appearance; she states:

Akousa: Hmmm. I've learned a lot. But I think the, the, I think the biggest one though is dealing with your emotions. Because you could be upset, you could be justifiably upset. You know, you could wanna flip a table and punch someone in their eye, but you don't do it. You keep that to yourself. And you, you figure out another way. You clean the house. You know, find a way to get rid off it, because at the end of the day, it's it's not worth it. And protecting the image of family is a lot bigger than your momentary lapse in judgment (laugh). Ummm, I find that, Ghanaian women, the older Ghanaian women have taught me, you know, ummm, not to face your emotions. Ummm, kinda pretend as if everything's okay. You know, keep, just keep going. Just keep going, just keep going, and even if the whole world's falling, just keep going. Okay, and you make sure that there's rice and stew in the house. Ummm, it's, I feel, I also feel like what I learned as a child, and what I perceived to learned or thought I learned, is also different once you actually get married.

Another important theme is the need to remain sexually pure. Akua and Akosua, the oldest of the participants, spoke about female respectability politics within Ghanaian culture and the pressure for the girl-child to remain wholesome. For most of the participants, sexual behaviour and expectation was almost never discussed, only assumed. The absence of such dialogue in their respective households led to a lack of knowledge in sex education, which in 
turn led to unhealthy relationships and stereotypes of their bodies and with boys/men. Both Akua

and Akosua had this to say:

Akua: So, I was expected to be respectful, I think my mother placed a lot of emphasis on my purity and chastity. Chas-tit-ty. Umm, my grandmother, umm, like she's a, she's a Christian, and I grew up in a Christian home. We when to church every Sunday, so my Mom put a lot of emphasis on that, ahhh, like I wasn't suppose to have, like a boyfriend. In high school, umm I couldn't have like boys call my house, on the phone, so I feel like that's one way that I was expected to perform gender as a Ghanaian--(in audible) keep myself...you know, umm, be respectful, and also umm, education. I think that was also more enforced from like my father's perspective

And...

Akosua: You know, umm, you know, I would like, you...I don't know for me, I felt as if, even before I knew what sex was, I felt like it was, it was the demon-thing. You don't do that. You don't, you don't have sex. You don't touch boys, you don't talk to boys. It was really weird. I see that they were tryin'a protect me, but at the same time, it was done in a such a freighting way, that it was just kind of like "ugh!,"..It's like once you get married, the truth starts to slip out. Like the truth of it all really kinda start to slip out, because they finally realize like okay you're married now, well I'm gonna tell you this, because this is what's gonna happen, and you're gonna have to learn to deal with it. Ummm--Wynnie: But it's almost as though they're setting you up to fail, it sounds like. Because, prior to getting married, you're not to, you, I can imagine that you didn't any conversations with your mother about, relationships, about sex, about any of that. But then you get married, and you're expected to know all of these things.

Akosua: Oh yeah. Umm, it's funny cause I remember..when I was away at university, ummm...I, I'm gonna say my mom pretty much knew I was dating, but, I, like, I had boyfriends, or assumed or accused I had boyfriends from [a young age]. But when I was away at university, I was dating this ummm, this guy...this ummm, white [guy], you know, very Canadian, like, you know, like his last name was like...probably on the boat that came over from England, and like, very very hundred percent Canadian. Umm, he...I had talked to my mum about him, because there was another guy that was tryin'a court me, and he was Nigerian, my mom actually spoke to me, and was like "yeah you should date the white guy" and, you know, like but there was, that was like one of the few times my Mum actually. like had a conversation with me about dating. Umm, there was one other time after that. But, that was cause I was like going through heartbreak, and whatever, she she kinda figured out. But, it feels like they, they really do set you up because, I didn't really get anything about sex. Sex was really what you learned off the streets. Ummm or in my case, what you learned at the library (laugh).

Even at very young ages, these participants were aware of their mother's discomfort in discussing issues of sexuality and sexual behaviour - a discomfort that perhaps is rooted in the fear of 
teenage pregnancy. As noted by Akosua this is an act that once again, could potentially threaten and damage the reputation and perception of what it means to be a good Ghanaian-woman.

\section{Identity}

When it comes to identity, there is often a forgotten element - that is the new space created when we exist in two different cultural spaces - and how that creates an additional narrative of identity and belonging that is a constant negotiation. The aim of this dialogue was to situate how the participants self-identity. In this section, I wanted to understand the hybridity of their Ghanaian-ness and Canadian-ness, and what each identity means to them, if any. The key inquiries here include: Would you identify as Ghanaian, Ghanaian-Canadian, Canadian? Why? What does being Ghanaian mean to you? What does being Canadian mean to you? Do you think your parents made a conscious effort to teach you about Ghanaian culture? If so, in what ways? In this discussion, I was particularly interested in how young Ghanaian-born women create and maintain their hybrid identities (their African and Canadian selves). I also recognise that there is much more to these participants than their African and Canadian identities. For instance, all three participants are descendants of different tribal groups within Ghana; however, this aspect is not included and/or addressed as it goes beyond the limits of this discussion, and with only three participants, such detailed foci could risk breaching participants' confidentiality. Nonetheless, it is important to highlight the limitation of the identity questions in this section.

The consensus with the participants is that they identify as being Ghanaian first, and then Canadian (Ghanaian-Canadian). For them, they have a close kinship to Ghana because it is their place of birth. When asked would you identify as a Canadian? Ghanaian? or GhanaianCanadian?, they each had this to say:

Adwoa: Because, like I said, I was born in Ghana, so that's where I grew up for a part of my life. And then both my parents are also very much Ghanaian. But, I've stayed in 
Canada for so long, that this is where I feel that I belong. So I would identify as a Ghanaian-Canadian.

Wynnie: So what does being Canadian mean to you?

Adwoa: Umm...honestly Canadian is my citizenship. I'm a Canadian because I am a Canadian Citizen. But I would always identify first as a Ghanaian.

Akua: I think for the most part, I identify as a Ghanaian. I feel really uncomfortable calling myself Canadian. Umm, just because I feel that I--like it's really hard for me to fit myself into the context, I like I identify a lot more with the Canadian culture--I mean, sorry the Ghanaian culture, a lot of my friends were there, umm, I'm more familiar with the system, and I've only lived here.

Wynnie: Okay-

Akua: --and it feels like, I'm just really starting to like get a grasp, like everything is just really starting to settle for me, so I've always sort of like felt in-between. It's sort of like I kind of like belong, but I don't belong.

Wynnie: Okay. Umm, (baby cry). What does being Ghanaian mean to you?

Akua: Oohh (laugh). That's a really difficult question--Yeah, so umm, I went to Ghana two years go.

Wynnie: Oh okay.

Akua: Umm, so the reason why went was because I hadn't gone back for five years. So, also I wanted to be able to examine the context and see if it was possible to work there. Umm, but I think that I really struggle with the whole idea of like Home, and the concept of it. Because I think, for Ghana, when you've lived here for some time, and you move back, you feel like you don't really fit into the--like you're considered like an insideroutsider.

Wynnie: Yeah

Akua: And that's really difficult and also sometimes you get really frustrated with how the system works (laugh). So, I don't know if...I think for the most part I would say that I identify the most with about Ghanaian culture would be like the food, umm, like the music, umm, also I guess the traditions that my parents have passed on to me, also I said that my dad is a [community leader]--

Wynnie: Okay.

Akua: So I know a lot of that stuff because I grew up around those things, but for the most part I think that's what I would say about Ghana.

Wynnie: Umm, what does being Canadian mean to you?

Akua: I think for me being Canadian is just having a passport (laugh)

Wynnie: (Laugh).

Akua: So...we're told that this is a place where we have so many opportunities, like you can do whatever you want to do, and I think actually when I moved here, my dad kept telling me how it's so easy, the education here, and I kind of felt it in high school, so I went into university with really good grades. And I had that same passion going to university, but then after, I graduated it was so difficult for me to find work-Wynnie: Okay.

Akua: That's how I started to see the, that's when I started to see how, like racism, and like identity and all these things play a part. It feels like when you're a Black person, like meritocracy doesn't really work, so like I don't know, it's really challenging in that sense, 
umm...So I don't know, I just feel like Canada, I'm Canadian in the sense that I have access, and also the ability to maybe, be independent--

Wynnie: Hmm

Akua: So (laugh), I think when I was growing up, I didn't really...okay so, when I moved here and I saw sort of like the images that people depict of Africa, and Ghana in general, I was quite disappointed because I didn't see that part of Ghana. I mean I've never, I haven't been to any other place apart from the [City B] Region, and the [City D]---and I went to school in [another region], but I haven't really travelled extensively within Ghana. And so when I see images of like, Ghana being like you know, like poor, and like children with flies on them, like the World Vision images and stuff, it's really surprising cause I never got to see that part of Ghana--

Akosua: Wow! Umm (pause). That's kinds tricky for me, but, but that's that's an identity question that I don't I've actually solved myself. Umm, I feel like I'm actually in-between, but I would say Ghanaian-Canadian, only because I was born in Ghana and raised here. That's how I justify it.

Wynnie: And you, you mentioned that you're in-between. What does that in-between stage look like?

Akosua: The thing is, it's like, because I came here when I was young, umm, I didn't get enough time to fully have an, an understanding of the culture that I was in. Umm, and then I moved here when I was young, so I, I feel like those couple years, those formative years, I didn't have them in Canada, so I had to kind of like, have them over again, umm when I first came. Umm, so I feel like, I always feel like I'm missing something. Like I always--there's there's, there's some big conspiracy and I'm missing something....Umm, but because of that, I always feel like I'm in the middle. Like I don't really speak the Akan language very well...or, but at the same time, I don't feel like I'm hundred percent Canadian, where I don't, I, where I feel like Canada's my homeland, you know, I praise it day-in and day-out. I also, I have an attachment to something. Later on--I don't know I have a pull towards Ghana. Right, but I'm, I grew up here, I'm Canadian. So.

Wynnie: Okay. That's dense. Thank you, laugh. What, but then, what does being Ghanaian mean to you?

Akosua: Ummm (pause), ummm (laugh), awkward (laugh). Ummm, being Ghanaian to me, I think in this point of life, where I'm at, being Ghanaian means, you know, seeing the growth in my country. You know, seeing the prosperity that's happening. But also seeing the nonsense that happens. Ummm, being Ghanaian to me means, you know, wearing ntoma, and you know, and repping it as hard as possible, even when you're Abroad. Ummm, being Ghanaian to me means, you know, enjoying the food, makinghaving that touch to the culture. Ummm, being Ghanaian to me, it means so many things, but at the same time I'm kinda like, I kinda still don't know what it means. Right, so I'm kinda throwing these things out there cause this is the life-stage that I'm at, and this is how I'm comfortable with it. But, being Ghanaian to me is just, it's just really just who I am.

Interestingly, Adwoa and Akosua (who migrated to Canada when they were both under the age of six) felt a closer connection with Canada and indicated that their inability to speak the 
Ghanaian dialect, Hausa, meant that there was an inauthenticity about their Ghanaian-ness. They both talked about being alienated by family members because they did not speak the language well. What became clear during the interviews was that language and the ability to speak their native language was important to the participants, and their inability to do so was a subject of contention for them. They also addressed their struggle with the English language upon arriving to Canada. Two out of three participants talked about not being able to navigate the English language upon migrating to Canada at an early age. Generally speaking, there is this idea that you are able to maneuver your respective society with ease because you have an accent that is familiar, common, audible and uncomplicated. And generally speaking, these accents include western countries and former colonizers. These accents are also highly racialized, so the closer one can get to sounding white (e.g., British, Canadian, American), the better.

For these participants, the conflicting expectations within the two cultures (Ghana and Canada), means that young Ghanaian-born women often struggle to find an identity that is their own. For instance, when asked what does the physical place Ghana mean to you? Akua, who spent the formative years of her childhood in Ghana, had this to say:

Akua: I think that there's a lot of wealth (laugh) in Ghana, which is concentrated in the hands of a few people, umm, I definitely saw that when I lived in [City B] for a little while. Umm...but I also think that in terms every infrastructure, like politically and I guess like socially, umm, it's inadequate, like Ghana really umm lacks, it lacks like a very strong system of coordination, like everything is just so haphazard.

In many ways, the participants felt a responsibility to both countries. They did not feel an infinite alliance to one country. For these women, it is nuanced and multi-layered. It is important to note however, the two out of three participants referred to their Canadian identity as "having a passport." This suggests that one can have an individual identity coupled with a social identity - 
a collection of beliefs about oneself in relation to membership in a relevant social group

(Postmes \& Branscombe, 2010).

\section{Transnationalism}

Transnationalism is a notable theme which includes the interconnected subthemes of citizenship and culture, all of which are notable within the narratives of the respondents. This is particularly evidenced by the response from the participants. When asked about the prospects of returning home, two out of three participants indicated they recently went back home to visit within the past three years. Moreover, all of the women indicated that they have plans to go back home to visit, as well as returning to live at some point. Adwoa noted:

Adowa: I opened a [business], so yes in the near future, once I've graduated from my program, I do plan on staying there for a bit to work.

Similarly, Akua had plans to stay connected to her motherland, as previously noted in the excerpt from her interview included above. Yet Akosua, the only participant who has not returned home had this to say:

Wynnie: Okay. What does the physical place Ghana mean to you?

Akosua: The physical name Ghana (laugh). It is, I don't know, it's like a beckon call for me really. I haven't been back since ' 91.

Wynnie: Okay. Do you have--and that was gonna be my next question, do you plans to go back or to, or to live?

Akosua: I wanna back and see it--with like adult eyes. Umm, I wanna go back next year, umm hopefully, financially, God-willing. Umm, because I like if I don't go back, I won't see my Grandmother. So, I wanna go back next year for sure.

As indicated in the above discussion on transnational activities, recent trends suggest that immigrants are moving across borders, while at the same time maintaining a pipeline between old lives and new worlds. The testimonies of the women reveal that they maintain national and transnational ties for two reasons. One, for these young women, Ghana means familiarity and learning ancestral connections and oral history. As articulated by all the young women in the 
study, they have a connection to Ghana and to extended family, particularly their grandmothers. This connection is a constant reminder of the need to return home. Secondly, the participants talked about the alienation they felt upon migrating to Canada. This alienation, according to one of the participants, "is a constant reminder that I don't belong." Thus, the connection they have with their motherland is intentional and deliberate. They seem to have an understanding of the two worlds/cultures in which they navigate. One of the participants asserts it as:

Wynnie: Okay, so then what does being Canadian mean to you?

Akosua: Umm, I think being Canadian to me, it means that I can be Ghanaian, but at the same time, I can be Canadian. Umm, I've never felt that being in Canada that I've had to give up any other of my identities. Umm, when I was growing up everyone kinda had, like a different background, a different religion, like, like, it, I found it more rare to find someone who was truly Canadian, and claim their Canadian status. Like, I'd find Italian kids who'd be like "yeah, I'm Italian-Canadian," you know, everyone would put something in-front of Canadian. Umm, so being Canadian to me is, is it's about diversity. Umm it's about, you know, accepting other cultures, and learning from other cultures. Umm, but it's also about trying to figure out where you fit in. Right? Cause that's not also clear.

Wynnie: And that's where you talk about that in-between space?

Akosua: Yeah.

For the participants, they understand that the cultures they live in are complex and at times competing. Yet, they have each found ways to negotiate, ways to be unapologetically Ghanaian, and intentionally Canadian. In many ways, these women will always have a connection to "home;" wherever they choose that home to be.

\section{Religion}

Another notable theme throughout the interview is that of religion. And while there were no direct interview questions about religion in the interviews, all of the women spoke candidly about the religious activities in their childhood. Church is central to southern Ghanaian identity. In this section, I am careful not to use religion and spirituality interchangeably, because the two are not mutually exclusive. Therefore, I will be referring specific to religion and the practice of 
going to church. When the participants spoke about church, it was often in relation to their

upbringing with their mothers and grandmothers while in Ghana. The women in this study made

several references to the act of going to church in their childhoods:

Adwoa: Umm, church is a huge thing for my family, especially for my mother. She's very like, "I love church...let's go every day." Umm (laugh), growing up I was probably in church like three times a week. So there was the Weekday Service, and then there was the Saturday Service, and then there was the Sunday Service, and umm it made our family a lot closer, when we were younger, but as we grew up and all of my siblings we started become teenagers and we need our independence, it became a struggle...almost like I had a power-struggle, my mum's like "you gotta go," and we're like "we don't we really wanna go today." Umm but like I said, it brought our family together, and it was a support system, it was another support system, so umm, the times where, you know, instead of going out into public, and then getting bad advice from friends, umm, I would have people in the church, who were responsible, who I could talk to about certain things, and we became very close. So individually it helped me, because I would've made a lot of horrible decisions if I didn't have that community to go to.

Wynnie: Laugh. Interesting. Umm, were they, were there any culture expectations of you as a Ghanaian female? If so, what were they? I think you just touched on a few.

Akua: ... I grew up in a Christian home. We went to church every Sunday, so my Mom put a lot of emphasis on that,

Akosua: My Grandmother is a big Roman Catholic. Like, like we're all Catholic, umm so I remember going to church with her. I remember learning like hymns, cause you're a kid, you know, you pick up things.

They also expressed a genuine desire to practice spirituality. Spirituality means different things

to different people. For these participants spirituality means something personal - getting in

touch with their inner-selves through private prayer, yoga, meditation and quiet reflection. When

asked about the important lessons learned from the women in her life Akua notes:

Wynnie: Okay, okay. Thank you for sharing. Umm, what do you think is the biggest lesson you've learned from the women in your family, about being a Ghanaian woman?

Akua: I think that, strength, and also (pause), I think strength for the most part, from my grandmother my mother, like I never realized it until now, my growing up, so like my mom would tell me and my brother stories about her immigration experience, and we would laugh about it. Like, she would tell me how, umm whenever she saw the cops she would be so traumatized because she didn't have her documents, and how when she had us, umm she had to work three jobs, but she was still very committed to like being a mother, and, and so sometimes when I go through really hard times, in terms of like you 
know, the structural barriers that I talk about, I just think about my mother, like she had very limited opportunities, she didn't have, she doesn't have a degree, umm, as I do, but she was still able to sort of like push through, so I really look to her for that. And I think my grandmother, she's just like a very peaceful person (laugh), like, and she's also very spiritual

Wynnie: This is your maternal grandmother?

Akua: My maternal grandmother. And I think--I say spiritual in the sense that, I mean I look to her as my Spiritual Mentor, and I don't use the word Religion because, I think that I'm also struggle with gender and how it comes together with religion, so I say spirituality because that's also helpful with my mental-health. So I look to her for that, yeah.

From the testimonies it is clear that these young women understand the overall importance that religion played in their childhood. For them, it would be easy to continue this tradition because the Greater Toronto Area has a large Ghanaian Diasporic community, which is highly involved in the church scene. However, their testimonies suggest that for these young women, it is not about going to church, but more about what they experienced as children and how that has become part of their identity.

\section{Isolation}

While the respondents in this study were not asked direct questions about feelings about isolation, they all spoke about social exclusion:

Adwoa: I could relate to my classmates because we were children, or teenagers growing up, we all had the same problems... but I also knew that I was different because there were things that I could not do that my friends were allowed to do, like sleepovers. But I never really thought of myself as being different.

Akosua also notes ways in which she felt a sense of loneliness and isolation from her non-

Ghanaian friends and says:

Akosua: ..you know, like I wasn't allowed to do things that my non-Ghanaian friends were doing. Umm, sleepover's, ahh no (laugh). Going to the movies? I wouldn't even ask. The most embarrassing thing is I didn't know how to explain that to my friends, because I knew they wouldn't understand. So, as I got older I learned to just pull away from friends so I wouldn't have to explain. It also made it very lonely at times, cos it meant I couldn't join the conversation sometimes. I had no idea what they were taking about. 
It became apparent during the dialogue that these participants learned to internalize their cultural difference into social isolation and alienation, as they learn to deal with social (Canadian) values that differed from their cultural (Ghanaian) values.

\section{Structural Barriers}

It is worth noting here that the respondents spoke about some experiences in both cultures (Ghanaian and Canadian) that were a result of structural barriers. The participants in this study spoke about structural factors in the Ghanaian cultural identity that influenced their socialization and identity.

Akua: growing up, my grandmother was always at our house. And when she wasn't at our house, I would be sent to stay with her in the village on my breaks from school. I would have to wake-up early and do all the house choirs. She taught me everything I now as a woman.

She notes similar experiences within Canada.

Akua: you know we're told to go to school, go to school and you'll get a good job. But nobody ever bothers to tell you about the other side of things. That beig an educated black woman doesn't guarantee you anything. And we'd like to think that we're not racist in Canada. But we are. At least in the U.S you expect it, it's kinda in your face, you? Wynnie: Hmmmm

Akua: I'm lucky to be in a profession that welcomes black people. But even at work, it's hard to see black people in management positions. And its sad, cos I feel like it's impossible to climb the social latter.

Likewise another participant notes:

Akosua: [my grandmother] she was tough, I mean I have a scar on my leg that reminds me of her. But she was tough in a gentle kinda way. She was almost like the breadwinner of the entire family. I don't know how she did it, but she was able to provide for everyone in the compound, equally.

Akosua: ... you know, it wasn't umtil university that I started really noticing all the racism and discrimination around me. Maybe because I was older. I know I've experienced it before, but it was until my second year university that I really started paying attention to it.

Wynnie: what prompted it? 
Akosua: I mean for the first time, I was surrounded by alot of white people. And I'm not even sure if it was discrimination or just privilege. White people have so much privilege, and I kinda want in on it too. I'm a person too.

The above discussion exposes some of the discriminatory experiences of the young women in both culture, and infers the prevalence of patriarchy and structural barriers. Similarly, the respondents talked about the struggle to develop positive cultural identity in Canada and indicated that this was further complicated by the negative stereotypes, racism and structural barriers within mainstream culture. Adwoa notes that she suffered low-self-esteem for a long time because she did not look like the images she saw in magazines and on television. While I did not ask the participants questions about racism and discrimination, it was apparent that the majority of the women struggled with their ethnic identity as a result of some of the institutional challenges that they faced.

\section{Conclusion}

In the narratives shared by these participants, family, gender, transnationalism/culture and religion have strong implications for feelings of belonging and identity formation. What we know is that immigrants are constantly living in a state of transformation, whether formal or informal. The conversations and themes that evolved from the interviews suggest these women have an intersectional understanding of themselves. In the next chapter, I move into an interpretation of the analysis, guided by the principles of Black feminist perspective, Criticalrace theory, and African Diasporic feminism. 


\section{CHAPTER SIX: DISCUSSION}

This chapter interprets my analysis of the data from the in-depth interviews from a Critical Race Theory (CRT) (Crenshaw, 1996), Black Feminist Thought (Hills-Collins, 1999) and an African Diasporic Feminist framework (Wane, 2007). In an attempt to do justice to this body of work, I could not stream-line my analysis within a single framework, and as such, have borrowed from three similar, yet distinct school of thoughts. As mentioned in Chapter Three, CRT, Black feminist thought and the African Diasporic perspective are all born out of civil rights and liberation movements. It is with this understanding that I seek to centralize the realities of Ghanaian-born women through a nuanced examination of their life stories. In addition, this chapter discusses how gender, race, social ties, and family all influence the identity of second and 1.5 generation Ghanaian-born women living within the GTA.

The chapter is divided into four sections. The first section provides an overview of the three theoretical frameworks. These frameworks allow the voices of the participants to resonate through, without filter. The second section highlights the major themes/findings through a critical analysis. Section three discusses the influence of family and social (religious) ties on respondents' sense of identity. The final section highlights the limitations of the study and implications for future research.

\section{Overview of Theoretical Framework}

In Chapter Three, I provided an in-depth analysis of critical-race theory, Black feminist thought and African-Diasporic feminism, all of which account for and influence my interpretation throughout this study. Below is a quick summary.

Critical race theory investigates power and the law, and situates white-privilege at the heart of oppression of marginalized people (Crenshaw, 1996). Although CRT has its roots in 
law, it also has proven an important analytic tool in the field of education (Cudjoe, 2005; Dei, 1996), offering critical perspectives on race, and the causes, consequences and manifestations of race, racism, inequity, and the dynamics of power and privilege in schooling. In this study, the participants reported feeling intellectually isolated from their White/Canadian counterparts in school, not because they were not intellectually capable, but participants felt that the system devalued their lived-experiences through the erasure of their histories. For instance, one of the participants shared moments of frustration in high school and notes:

Akua: As the new kid from Africa, I was often afraid to speak up in class, not because I was not smart enough, but because my teachers treated me different from the other students. Perhaps it's because I had a thick African accent. But my accent is not an indication of my intelligence, is it?

For many immigrants, the ability to speak English is a marker of success. A recent study in Vancouver's African immigrant community confirmed that many Africans experience what is called "linguistic capital erasure" (Creese, 2011, p. 300), whereby their thick African accents signaled a lack of intelligence, a lack of expertise/authority and a lack of modernity. The privilege here is having a "Canadian" (read: white-ish) speech pattern, which signifies intellect and knowledge as some marker of success (Thiong'o, 1988). With regard to education, the participants noted that they often felt disenfranchised and lost within a curriculum that was culturally-specific and intellectually exclusive. The testimonies about school experiences showed that participants are aware of how one differs as an African body in a predominantly white education system, and the implications this has on one's success.

Racial discrimination forms a major issue in the analysis, as many participants experienced racism; however, it did not account for their sense of identity in the early years of migration. While the participants discussed experiences of racial discrimination (as adults), this study reveals that first and 1.5 generation Ghanaian-born women were not inherently aware of 
their differences as children. In fact (outside of language) the three respondents in this study noted that they did not think much of their race prior to and upon arriving in Canada. One participant notes while she was aware of the differences in "rules and expectations at home," she did not think of herself different from her classmates and her friends from other communities. Manuh (2006) and Coe (2008) argue that immigrant children are often not inherently aware of the differences with children in the host county. For the respondents in this study it was more about finding ally-ship in other children. They did however, highlight the racial tension they felt in their adolescent and adult lives, and attributed this to misrepresentation of the black female body and institutional racism. Two out of three participants also noted feelings of isolation and discrimination at the post-secondary level. All of this reveals the racial and discriminatory experiences of Black persons in Canada. It also makes the multicultural and diversity rhetoric within Canadian systems all the more dissonant from the everyday experiences of immigrants. CRT's ability to call into question the disconnection between real-life experiences (practice) and the system (law) (Crenshaw, 1996), speaks truth to the narratives of these young women.

More specifically, Black Feminist thought is about the first-hand investigating of black women, by black women themselves. As mentioned in Chapter Three, Black Feminist thought is an important analytical tool and framework in any inquiry about black women because it provides a narrative process direct from the subject-matter. Further, this paradigm is about selfdefinition and self-valuation, and seeks to counter the single-narrative of the black/African woman. Fundamentally, it is about finding alternative ways to produce knowledge about the black/African female body and consciousness-raising (Hill-Collins, 1999). The oral narratives of the participants illustrate that African women are beginning to find new tools of resistance, and finding value in experiential versus theoretical (research) knowledge. 
Akua, one of the participants, notes that she is a member of a prominent Black Action group in her community as a form of support:

being involved in a ummm, the [Black Action Group] that I said, I've been exposed to different black women, who have been really supportive. I think you have to put yourself out there, in a sense, but also, I think we also have to be proactive in like, asking [for help].

For this participant, part of being an African woman means finding allies in other positive black women. This means holding each other up and holding each other accountable, and saying your narrative is meaningful and important. Another participant also noted that African women require a counter-narrative, because we (African women) absorb the negative representation in the media at a larger rate. From a Black Feminist perspective, these participants stress the importance of detoxing psychologically from the portrayal of images that African women take in from popular culture through collective consciousness-raising.

Lastly, African Diasporic feminism is a nuanced paradigm that seeks to deconstruct and re-construct the image of the African woman and involves critical interrogation of structural powers and the oppression of African women on the continent and throughout the Diaspora. Unlike western feminism, African Diasporic feminism does not focus on patriarchy, but is more concerned in working collaboratively for the empowerment of the African woman. Unlike Black feminist thought, African Diasporic feminism is about theorizing the perspectives and experiences of Africans on the continent and in the diaspora. It is about reaching across political, economic, and social lines to work collaborative (Wane, 2007). Akosua highlights this well when she notes:

I think for me, I spoke a lot about being in the middle, umm, and accepting that our dynamics, like our family dynamics can be really messed up. And that it's okay to look outside. I think that our community fears letting outsiders in. Maybe it's fear of rejection. But I think there's a lot to be learned from other cultures and communities. It's not 
always about us against them. Just as other cultures can learn from us, we too can learn from others. I think it's time we opened up those doors, you know?

But similar to Black Feminist thought, African Diasporic Feminism is about centering the experiences and identity of African women and raising-consciousness. Similarly, African Diasporic Feminism exits within cultural, historical, and generational contexts.

The above discussion frames what will proceed in the next section. As mentioned earlier, my findings from this study is analyzed and understood from a critical interrogation of the systems that help to create and maintain marginalization of Ghanaian-born females. My analysis seeks to provide and represent the nuanced relationship that these women encounter with their Ghanaian and Canadian identities.

\section{Major Findings and Themes}

From the personal interviews, I found several important themes: extended family, identity, gender politics, transnationalism, religion, isolation and structural barriers. I explore these themes more fully below through the lens of my theoretical framework and the literature review.

Extended family. Extended family is one of the first notable themes throughout the narratives of the respondents and refers to aunts, uncles and grandmothers. The women in this study make reference to relatives, biological and non-biological who lived in the same household or compound. Therefore, the use of the term extended family will always refer to relatives outside of the traditional nuclear family. Secondly, the participants' use of the word identity was often in reference to their unique qualities, and characteristics as Ghanaian and Canadian women. My use of the term will always refer to the contextual labeling of the participants as Ghanaian-Canadian. Here, I am not particularly interested in their Ghanaian-ness or Canadianness, but the emphasis is on how they occupy the in-between spaces, in a way that makes sense 
to them. Third, gender politics in this study refers to the roles, responsibilities and expectations of the participants (as young-women), juxtaposed with the roles and expectations of the men (fathers, brothers, uncles, cousins) in their lives through the lens of two patriarchal cultures. Next, transnationalism in this study refers to the physical, economic and social migration of the participants from their homeland into Canada and vis-a-versa. The transnationalism that the participants talk about involves cross-cultural acts and ways of living/being. Religion was a major influence in the participant's childhood. And here, religion is understood and discussed in two ways: the act of attending church, and spiritual relationship and practices. Another notable theme was isolation. The participants spoke honestly about having feelings of alienation and isolation (some of which was internalized) as they struggled to form friendships and social networks.

With that said, the first part of the interviews focused on participants' childhood. Some of the key questions were: where did you grow up? Tell me about your childhood. I found several important themes within the responses. First, we talked about how the participants were raised by extended family, specifically their grandmothers. Overall, the participants expressed appreciation and respect for their grandmothers. They were described as being "strong" or "resilient." Akua spoke about her grandmother's ever-presence and influence in her childhood. Likewise Akosua also noted her admiration for her grandmother growing up. In her work, Davis-Sowers (2012) notes that popular knowledge and discourse around the family does not address, nor reflect the diverse communities within the Canadian landscape. Along with this, dominant discourse around family fails to incorporate cultural relativity, extended family structures and spirituality; this is certainly true for many indigenous communities (Davis-Sower, 2012). African grandmothers hold a unique place in the family unit. Their lives often center on the needs of family rather than 
the needs of their own (Collins, 2000; hooks, 1984). From a black feminist perspective, the decision to care for their grandchildren is guided by not only the need to nurture. The narratives of the participants suggest that they recognize that it is a historical and cultural obligation and responsibility for African grandmothers to be caregivers. One of the participants states that in her small village, all the elderly grandmothers and mothers were responsible for every child. She notes: "in [City A] anybody's child, was everybody's child. And my grandmother was the one to be feared, not in the sense of fear itself, but she would discipline you regardless of whose child you were. And then feed you." The participants understand this practice to be a cultural norm in Ghana as they view their grandmothers as transmitters of cultural and traditional customs. In many ways, our personal understanding of grandparents, involves a continuum of relatives/caregivers, who take on the task and responsibility of caring for children who are not biologically their own children. The position of grandmothers as transmitters of culture and cocreators of life is devoid in parenting literature (Davis-Sowers, 2012). This in turn, does not value the lived experiences of grandmothers, and at the same time, deems them and their labour as disposable. But the testimonies from the participants suggest that grandmothers are integral to their childhood, personhood and overall identity. Moreover, grandparents signify culture and tradition, and represent a pipeline between generations, through the use of oral history.

Similarly, along with being raised by extended family (grandmothers), many of the women cited being raised in lone-parent households - that is, being raised without their respective fathers. Akosua for example, met her father when she was between 5-6 years-old and characterizes this experience as typical of a migration pattern, in which men leave their home in search of a better life abroad. In recent studies, both Manuh (2000) and Mensah (2002) note the masculinisation of migration, in which the global North made preference in the immigration 
systems based on education and professional migrants (who were often men). This frequently resulted in lack of access for women, who were left in their home country to take care of children, and other extended family members. In the late 1980's Canada became a popular destination for Ghanaians fleeing economic and social instability as a result of a coup against the socialist Nkrumah regime (who ruled from 1957-1966), and the rise of military rule under Flight Lieutenant Jerry John Rawlings (who ruled from 1980-2000) (Opoku-Dapaah, 1996; Oppong, 2004). Many Ghanaians fled their homes as a result of human rights abuses, differing political opinions and confiscation of property. Some left as a result of decreasing employment opportunities, but others (mostly men) left due to the political situation. Opoku-Dapaah (1996) notes that Ghanaian migration patterns occurred in two waves: the first wave began in the early 1970s to 1986 and the second from 1990 to present. In 1996, an estimated 14,935 Ghanaians migrated to Canada, with 10, 025 (67percent) residing in Toronto (Statistics Canada, 2000). Unlike other immigrants, many Ghanaians arrived based on education and professional skills, at a time when Canada's immigration policy was based on a point system. This meant that prospective immigrants were evaluated based on "age, education, and occupational demand irrespective of their racial and ethnic background" (Mensah, 2002; Oppong, 2004). A report by the Department of Citizenship and Immigration (DCM) found that there were a hundred men for every forty women in first wave of migration. This trend was consistent through the mid-nineties to present, and speaks to a larger system of patriarchy and sexual division of labour. During the 1980's the Canadian government made amendments to the refugee system, that favoured professional and highly educated individuals. This, coupled with women's lack of access to resources in Ghana, meant that the majority of immigrants were men. Moreover, the majority of Ghanaian women were considered unskilled labourers-petty traders, cocoa farmers, stay-at-home 
mothers (Manuh, 1994; Opoku-Dapaah, 1993; Oppong 2004;); the majority of whom remained at home because they were responsible for children and other extended family members. Women migrated mostly as wives, sponsored by their respective partners. This pattern of migration is reflective in the narratives of the participants - a common experience where men would migrate first, then sponsor their wives and children through the family reunification process (Manuh, 1999; Mensah, 2002; Opoku-Dapaah, 1993; Oppong, 2004; Wong, 2000).

All of the young women in this study cited experiencing a disconnection with their respective fathers, and ultimately their home-life. One respondent described it as "a meeting of strangers." The tension experienced between Ghanaian-born females and their fathers is an area that also needs further investigation, as it speaks to a larger discussion about parent-child relationships in the face of migration and gender-politics (Coe, 2008; Manuh, 1999) within the Ghanaian household, which I explore further in the next section. But, the narratives that these women tell about their migration experience and home-life is more about relationships, community, extended family, and the ways in which all of this is complicated by the amalgamation of various cultures, and by life in the Diasporic.

Another significant disclosure from the interviews was about Ghanaian culture and gender politics, specifically in terms of sexual behaviour. There is an understated high level of sexual conservatism within the Ghanaian culture (Manuh, 1999), one that renders women's bodies to be regulated and policed by men. It is important to note here that men are afforded sexual privilege, in which they have a different kind of "sexual independence" (Manuh, 1999, p. 61). In one instance, Akosua relates a story in which it was more acceptable for her much younger male cousin to have a girlfriend, which speaks to the gendered privilege that is afforded to Ghanaian boys/men in many households. 
Even in their adult lives, many of the women expressed that they find it difficult to talk to their parents about their sexual life. According to Daniel, Feather-Stone, Hooper and Scourfield(2005) this kind of conservatism is reflective of how children gravitate towards and internalize models of their respective gender within the household. The conversations also highlight ways in which pre-marital/teen pregnancy in Ghanaian households has been constructed by parents (elders) and assumed by Ghanaian girls. Akosua's statement suggests that the reluctance to talk about sexuality within the home comes from the fear of not only pre-mature pregnancy, but also pre-mature pregnancy outside of marriage. It also appears that parents are more preoccupied with the policing of their (daughter's) bodies than the teaching of sexuality. Both Akosua's and Adwoa's narratives speak to ways in which women internalize a conservatism of sexuality and sexual practices, and how sexuality and culture gets coded on the female body (Mohanram, 1999).

But these women also describe the ways in which they resist against all the sexual conservatism. Both Akosua and Adwoa find sources outside of the home to confide in about such matters. Adwoa for example, confides in friends at church, while Akosua refers to her friends at school for appropriate/current information about sexual behaviour and sexuality. And while it would appear that Adwoa and Akosua gravitate towards the sexual conservatism of their parents, they also express that there are moments when this traditional way of thinking about sex/sexual behaviour does not appeal to them. This reveals the particular pressures that young women, growing up in two contrasting cultures, often experience (Coe, 2008; Manuh, 1999).

For these young women, being a female in a Ghanaian household means being caught between Western norms and Ghanaian expectations, as they find themselves battling between cultural expectations and their personal desires. There is a taken-for-granted assumption of 
gender-roles in Ghanaian culture (Agyekum 2012; Coe, 2008; Kitson, 2003; Manuh 1999;

Owusu, 2006), one which renders these young women voiceless at times. For example, all three participants spoke about the expectation to get married, and to know how to cook traditional Ghanaian food and take care of a (nuclear) family. While knowing how to cook is certainly an important asset, this responsibility is especially imposed on young women. Akua describes experiences in which she has to cook for her (older) brother:

Akua: I currently live with my older brother. And although he can cook, he refuses to do so, because he just expects me to do it for him. There are some traditional Ghanaian dishes that he can probably make better than me, but he refuses. When I complain to my mom, she just says, 'you can't expect him to cook, you're the female in the house.' For me, you should learn how to do things for yourself as a man, so that you're not depending on a female, or what if you get married and your wife becomes ill and can't cook for you? What do you do?

Such cultural expectations represent a challenge for Akua, as she has learned to develop her own value system and being raised in a Canadian context. She hesitates to accept certain cultural values because she grew up in a Canadian society that has encouraged her to challenge assigned gender roles.

These young women also expressed the frustration that on the one hand, parents teach them to be strong and ambitious, but then they are challenged, judged and criticized for living in and through this strength. This certainly raises a question about what gendered roles should look like in Ghanaian communities, which often presents a challenge to Akua when interacting with men in her community. This reveals that Ghanaian women battle a number of myths and expectations that do not reflect their goals or aspiration; they are in a constant negotiation and rearticulation of their identity. In her study, Manuh (1999) finds that there are a number of stressors that contribute to and inform gender awareness and relations among Ghanaian immigrants; these factors include consciousness of women's rights in Canada, access to 
resources, and education. Baffoe (2011) also found that African youth in Canada are confronted with a number of issues that contradict the values and attitudes promoted in their families and ethnic cultures. Both studies acknowledge the stress these factors cause for immigrants from Africa as they straddle their two worlds within Canada. While all three participants may not agree on all aspects of this culture, they still express a strong desire to pass down cultural traditions and customs to their children. For them, it is about finding ways to create and reconstruct a "bi-cultural identity" (Baffoe, 2011, p. 483).

Another important theme which emerged out of the interviews is the way in which the Ghanaian community relates to other Black communities. For example, all three women spoke candidly about how Ghanaians perceive other black communities, and vice-versa. Akosua and Adwoa indicate that growing up in Brampton, most of their friends were not aware of Ghana. They spoke about how people either thought they were from "the country Africa" or that they were Caribbean. Akosua remembers adopting a "Jamaican persona" in order to fit into the culture at school. Akua on the other hand, notes finding allies in other continental African communities/students in school:

Akua:...in high school, I had one really close friend. She was from [Zambia]. A lot of my friends were International students in university. I don't think I realized this at the time, but I gravitated towards continental Africans. Perhaps because they reminded me of my friends in Secondary school in Ghana.

Akua's comments were interesting in that, she believes that continental Africans are able to create more of a bond in the Diaspora - based on similarities in cultures, through a sort of cultural hegemony. Yet later on, Akua goes on to explain that the similarities and solidarity shared between and amongst some African communities does little to prevent marginalization in the respective communities. 
Okeke-Ihejirika and Spitzer (2005) contend that in the face of racism and discrimination, African youth find ways to mobilize and support each other; however, this often is compounded by ethnic, cultural and religious clashes amongst themselves. Akua does not necessarily believe that the experiences of Ghanaian-born youth are unique; most immigrant communities/cultures will have to confront this question of cultural adaptation (Baffoe, 2010; Humphrey, 2007; Kumsa, 2005), which refers to the process of assimilating and adjusting one's beliefs and values based on one's social world/ environment. Although Akua is a member of a popular Black community organization [in Toronto], as a form of building alliance, she fears that she will have to perform and assimilate to particular narratives of blackness, and fears she will lose her Ghanaian culture in the process. For these participants, growing up in Brampton/Toronto meant that there was no Ghanaian-self, only a Black or African identity. Tettey and Papulampu (2005) allude to the cognitive dissonance continental Africans often experience when interacting with other black communities, because they (African youth) have to compromise their Africanness, in order to be treated with dignity.

Adwoa recounts her first experience of Black History celebration at school and the confusion and pride she felt simultaneously, because for her, she is African every day, not simply in February, and yet proud because her culture and physical-body was being represented and appreciated. This speaks to the paradox many continental Africans feel within the school system. In their research of the Canadian education system, Dei, (1997) note the underrepresentation and misrepresentation of African and Black histories/identities within the curriculum, and the impact this has on student success. Akua, who went to a predominantly white university, reports her frustration with the lack of diversity on campus and in her program. She says:

The first year of university had to be the hardest for me. I went to a school where it was like $2 \%$ black people. And even in my program, there was such a lack of diversity that I 
wanted to transfer to another school. But I did join the Black Student group. But even that was hard, because there was so much tension between the Caribbean and African students. I couldn't understand why we couldn't make it work. I mean there were only like 10 of us.

Adwoa in particular notes that she would not have made it to high school without the intervention and counselling of her Grade 7 teacher (who also happened to be a Black woman). She noted that high school was particularly difficult because she was trying to find herself, and this teacher intervened with the right resources (through counselling and affirmations). This links back to Black Feminist thought and the importance of providing and creating support, accountability and agency for and amongst black women.

The various comments made by the women about their social and educational experiences corroborate the findings of Agyekum (2010), Cudjoe (2005), and Okeke-Ihejeirika and Spitzer (2005), noting that first and 1.5 generation may experience more racism and discrimination in education and employment, than their parents because of their ability to speak English like other Canadians, their educational attainment, and their high expectation of the rights that come with citizenship. These factors place them in positions where they are more likely to identify their experiences as racialized and/or marginalized. But irrespective of the gatekeepers of knowledge and identity, the response from these participants reveal that they find ways to be visible and relevant, all the while resisting the stigmatization of simply being African in the social and political context.

Migrations and transnational ties. The findings in this study suggest that the participants understand life in the diaspora as being temporary. Although they were exposed to life in Canada at an early age, the women in this study understand that their identity is not tied to one country or location, but rather that one can acquire an individual identity by acquiring a collective identity as well. These young women recognize that their unique identity (as young 
educated, single or married women), does not stamp out their collective identity, and that these things are not mutually exclusive, but work together to inform who are they. In fact, Appiah (2005) notes that identity is a large and often abstract social category through which we define ourselves. Coupled with migration, identity is a social system that links people and their practices across space and time. The findings in this study also suggest that Ghanaian migration for these Ghanaian-born females is linked to transnational identity and patterns such family, community, food, music, and clothing. The young women in this study articulate their migratory experience as being directly linked to transnational activities. For example, all of the participants stated the desire to stay connected to Ghana. Akosua says:

When I was younger, I didn't listen to Ghanaian music at all. Now, I play it in the car just as much as I play my rock, R and B, or hip-hop. Ghanaian culture is so easily accessible now. When I talk to my cousins back home or see them on facebook, I can't believe some of the things they say or do. Listen Ghana is a different place.

Akosua's testimony suggests real ways that children of immigrants are connecting to their homeland. Transnationalism itself as a process is something which has been over-used to describe various aspects of resettlement (Clavin, 2005; Vertovec, 1999; Wayland, 2006). But as a political dogma, transnationalism encompasses many policies and processes. As a result, I do not believe there can be one explicit definition of the term. But I also believe that transnationalism is not about terminology or the end result, but more importantly, it is about the process.

For the purpose of this study, the discourse of transnationalism refers to the practice of cross-bordering and "multiple ties and interactions linking people or institutions across the borders of nation-states" (Vertovec, 1999, p. 447). Karjanen (2012) conceptualizes transnationalism as an "understanding of how migrants move circularly between their country of origin and that of their destination-[resulting in] social, cultural, political and economic ties 
across borders" (p. 165). Other theorists conceptualize transnationalism as "the processes by which immigrants forge and sustain multi-stranded social relations that link together their societies of origin and settlement" (Bosniak 2003, p.35). Notably the common premise here is that transnationalism enables people to live in two separate worlds concurrently, eventually bridging these worlds into a single unified world/reality. In essence, transnationalism is about the renegotiation of identity and ability to migrate and settle in one nation, while yet still maintaining connections with one's homeland. One of the participants noted that she would like to visit Ghana with her husband for their honeymoon, because, as she as she puts it "Ghana is the new Europe." Currently transnational trends within the Ghanaian community involve social and cultural implications, which I discuss below.

Our current global village makes it difficult for us to ignore the impact of transnationalism and globalization, because transnationalism is not only about the movement of people, but also encapsulates the cross-bordering of commodities and capital. As such, we are all influenced and impacted by the effects of cross-bordering at the social, personal, economic and even psychological level as these participants illustrate. Unlike previous migration patterns which was characterised mainly by long-term- habitation (with migrants moving to outside countries permanently), contemporary transnationalism can be either short-term and/or longterm, temporary and/or permanent (Portes, 1999; Wayland, 2006). This is particularly evidenced when Akua, of the participants indicates that the idea of home is an abstract concept because she was considered as a foreigner when she returned to Ghana recently.-This participant's struggle with the concept of home has been extensively addressed in a study by Michael Baffoe (2011), in which he examines the "deconstruction and reconstruction" (p.160) that many immigrants face in their plight to navigate their new world. According to Baffoe (2011), African immigrants are 
involved in an "emotional, cultural, economic and social readjustment" (p. 421) of home, one that renders them as both insiders and outsiders. And while all three participants do not see themselves living in Ghana permanently, they do express a strong desire to return to Ghana at some point in their lives.

All the participants also expressed a strong responsibility to Ghana, inferring that the 1.5 and - first generation have a loyalty to their motherland, whatever that loyalty may look like. In a compelling study, Owusu (2006) found that Ghanaian immigrants maintain transnational ties through various avenues, including cash remittances, transnational humanitarian aid, and cultural associations in the Diaspora; he also notes that such ties have influenced younger generations ${ }^{3}$ to invest in their home country. These experiences, coupled with the recent rise in Ghanaian music (hip-life), fashion, and food in mainstream American media, has made it more enticing for Ghanaian youth to also embrace their home-land.

The testimonies of the participants suggest that they maintain national and transnational ties for several reasons. One, for these young women, Ghana means familiarity and learning ancestral connections and oral history. As articulated by all the young women in the study, they have a connection to Ghana, to extended family, particularly their grandmothers. This connection is a constant reminder of the need to return home. Secondly, the participants talked about the alienation they felt upon migration to Canada. According to one of the participants, this alienation is a constant reminder that she does not belong. Thus, the connection they have with their motherland is intentional and deliberate. They seem to have an understanding of the two worlds/cultures in which they navigate. For the participants, they understand that the cultures they live in are complex and at times competing. Yet, they have each found ways to negotiate -

\footnotetext{
${ }^{3}$ Also referred to as first generation and 1.5 generation.
} 
ways to be unapologetically Ghanaian, and intentionally Canadian. In many ways, these women always will have a connection to home wherever they choose that home to be. Lastly, the testimonies suggest that culture and identity are important in the Diaspora. For them, there is a link between identity and culture.

The relationship between migration, representation and identity are all paramount to transnational activities. In terms of migration, representation refers to internal and external discourses (Bloemraad, 2004). To say it another way, internal representation is about ways in which migrants perceive themselves and self-identify. External representation is signified by how others view migrants, and is articulated by dominant culture within a receiving country (often through White-supremacist-patriarchy). Often times, external players are the gatekeepers, who determine who gets counted in and who is considered an outsider. Migrants often have individual social identities which are developed in the country of origin, and transferred across borders into receiving countries. But often, such identities are stripped from them and reconstructured by the ruling class. This is evidenced in this study and elsewhere (Agyekum, 2012; Kitson, 2003; Manuh, 1999; Wong, 2000) where the narratives and identities of AfricanCanadian women have been sculpted for them by dominant groups. In their studies of AfricanCanadian women, both Donkor (2000) and Wong (2006) posit that transnationalism and identity formation in the Americas has created false notions of citizenship, belonging, identity, diaspora and home for African women in postcolonial migration. The testimonies in this section suggest that young Ghanaian-born women lead multiple lives, with complex multiple fluid identities, where they are reconstructing and renegotiating their identities daily. But dominant discourse around their identities only offers a single narrative, with unintended consequence of cultural and intellectual erasure. What is clear from these young women is that their Ghanaian-Canadian 
identity is constantly changing, and requires a holistic and nuanced examination that goes beyond their status. The narratives of these young women offer multiple voices/identities against the backdrop of a single African identity/story. But it is impossible to talk about the single-story without talking about power. Stories are defined by the dominant groups, whereby dominant groups are responsible for how stories are told, who tells them and when they are told. And because the storyteller is often the ruling class (white, European, male), they are able to create a uniformed/single story, while offering multiple narratives around their own identities. This also means using their power to make the story the only narrative being told and maintained about marginalized groups. The single story creates stereotypes, but stereotypes are often incomplete and not holistic of any one thing. In essence, there is never a single story of any one thing or any one identity, only the powers that create them.

Religion. Timothy Smith (1978) notes that migration itself is often a theologizing experience, through the application and resettlement process, because religion provides a moral and cherished resource for immigrants as they try to navigate resettlement in a foreign land. Studies show that immigrant churches help to foster and broker the in-between space experienced through migration (Bankston \& Zhou, 1996; Breton, 2012; Ebaugh \& Chafetz, 2000). In his study of Ghanaian churches in Toronto, Mensah (2009) contends that churches have become sites where social services are provided, and where identities are maintained. It is interesting to note the various ways in which Ghanaians are by nature highly spiritual and religious people ${ }^{4}$. Ghanaian women in particular, often bear the responsibility of being transmitters of culture, and in so doing, also service as spiritual leaders. Notably, Hill-Collins (1999) asserts that historically (African) "women are expected to bear the culture by giving birth

${ }^{4}$ According to Statistic Canada in 2001, 93 percent of Ghanaians reported being Christians; only 2 percent of them reported being Muslims, and 5 percent declared no religious affiliation. 
to it and nurturing it" (p.148), and this can be said for religion as well. African feminist scholars such as Amenga-Etego (2012) suggest that religion is also a highly gendered process in Africa. A closer examination of religion in Africa suggests that while men are the primary leaders of religious institutions, women account for more than $50 \%$ of the congregation in most churches (Amenga-Etego 2012); this trend continues in Canada, were women account for 58 to $60 \%$ of Ghanaian congregations (Mensah, 2009). Amenga-Etgo articulates that "the emergence of a gender specific spirituality in African Christianity has its bearings in the continent's pervasive religio-cultural and patriarchal systems" (2012,p13). But the new generation of women are calling for a joint responsibility and leadership by both men and women in their Christian faith and society, according to Amenga-Etego (2012) and Mercy Oduyoye (2002).

This finding is not new, as many previous studies have documented similar findings. Mensah (2009) and Oduyoye (2002) have documented the religious activities of Ghanaian immigrants in the diaspora and found that Ghanaians are by nature religious and spiritual. The testimonies of the young women in this study reveal that religion is a major component of their Diasporic journey. These testimonies refer to religion in the aspect of both attending church and spirituality (meditation, prayer, yoga, solitude-connecting with the inner self). Although there were no direct questions about religion in the interviews, all of the participants spoke poignantly about attending church with their grandmothers, and later on with their own mothers while in Canada. They also spoke about the socializing functioning of church. Adwoa says:

growing up most of my friends were at church. Me and my siblings went to church because it meant that we could get out of the house, it was actually the only other way for us to be around other Ghanaians.

In fact, one would be hard pressed to find a Ghanaian youth in the GTA who has not attended church, albeit as a form of socializing. For the Ghanaian community in Toronto, this has become 
a way of life. Mensah (2009), for instance, reported in his study of Ghanaian churches in Toronto that they (churches) serve as ambassadors and provide a number of social services, ranging from English as a Second Language (ESL) classes, marriage counselling, financial and legal assistance, to conflict resolution, mentoring, sports and summer school programs for the youth. In fact, most of the research reveals that Africans use religion and church to form social capital (Mensah, 2009) and to reproduce their cultural identity (Amenga-Etogo, 2012).

In terms of spirituality, two of the participants spoke about their spiritual journey. What is interesting about this is that they spoke about it outside of the context of the church. Coupled with their exposure to Canadian culture and higher/critical learning, it seems that these young women do not see their spiritual growth as only being in church. For them, it is a holistic relationship between their mind, body and soul—a practical sanctity. Spirituality in African religion is a highly gendered-specific process as well. One of Africa's leading scholars on religion and spirituality, Oduyoye (2012) characterizes it in the following excerpt. She notes:

Women's spirituality is qualitatively different from that of men because women's experience of socioeconomic realities differs from that of men. Similarly, women's dependence on God tends to be expressed more overtly; hence, their dependence on religious beliefs, practices, and ritual is more intensely demonstrated. When women read the bible, they often hear what is unheard by men. Thus, women's biblical theology originates at a different depth.

African spirituality is rooted in indigenous and sacred understandings of ancestors, divinity and other spirits (Amenga-Etego, 2012), all of whom worshipped and respected the land. However with the arrival of Christianity, many Africans, Ghanaians included, have shifted from traditional rituals to mainstream practices of religion, and anything outside of this is considered to be witchcraft and occult. For instance, Akua notes the following:

My mother is a religious conservative. So for her, spirituality is just about going to church. She doesn't like to see me doing yoga, because she thinks I am calling spirits. For me, yoga helps me with my mental health. 
While I did not ask about their spiritual life, it was clear that participants felt some responsibility to maintaining this tradition. Perhaps this is not yet an option that all the young women have considered, but participants understood the overall importance of existing and functioning in a spiritual world, traditional and contemporary.

Isolation and structural barriers. These two themes were not as prominent as the other themes noted, which is understandable as they were not key concepts raised in my research questions or the interview questions. However, elements of both these concepts emerged in the interviews, during my analysis. I discuss these briefly below.

Current research on immigrant children has highlighted the many ways that children and youth experience migration. With the move away from the deficit model, which poses that minorities are different because their culture/identity is subservient from dominant groups (Chaung \& Moreno, 2012; Coll \& Marks, 2012; Igoa, 1995, Wayland, 2006; Williams, 1992; Yesufu, 2005), some researchers who explore ethnic minority and immigrant children are beginning to recognize the lack of consideration for ethnic sensitivities and socio-cultural context in their analysis. Immigrant children/youth face a myriad of challenges which include language, acculturation, psychological and socioeconomic struggles (Dei, 1997; Gariba, 2009; Kitson, 2003; Kobayashi, Kumsa, 2005; 2008; Mensah 2002; Opoku-Dapaah, 2006; Oppong, 2004; Owusu 1994; Rambuat, 2004; Zaami, 2012) and feelings of isolation has been identified as one of the leading issues among them.

Current research on immigrant children/youth and the process of acculturation also suggests that older children struggle to make social connections because they migrate at an age where peers have already created networks of friends (Coe, 2008; Manuh, 1999; Okek-Ihejirika \& Spitzer, 2005; Owusu, 1994; Rumbaut, 2004; Yesufu, 2005; Zaami, 2012). As a result, many 
experience sociocultural challenges, which is at times is further complicated by language barriers, as well as psychological and emotional struggles (Opoku-Dapaah, 2006; Owusu, 1994; Tettey \& Puplampu, 2005). The adjustment process of migration means that immigrant children experience emotional instability due to changes in language, cultural values, practices and norms.

The findings in this study validate the findings of other studies, which note that immigrant children/youth find it difficult to make a smooth transition into the host country due to conflicting cultures (Agyekum, 2012; Kumsa, 2005; Manuh, 1999; Owusu, 2006; Rumbaut, 2004). Many of the participants noted feelings of exclusion and isolation from their peers, Adwoa notes:

...the transition was really hard for me. I remember going into school and having people who were trying to be my friends, trying to talk to me, and I would beat them up, literally, because I thought they were insulting me (laugh)...they have all their friends alrady so I was always the odd one out, ummm, always trying to find my place, and always trying to fit in.

Akua also supports this tension:

When I started school it was very hard. It was very hard to make friends because I wasn't allowed to do a lot of things that my classmate were doing, like going outside to play, going to birthday parties, to the movies. So I really didn't have much to talk to them about. And because I was the only African in my school, it felt really lonely.

The young women in this study spoke about experiencing and facing individual, family and social challenges in trying to negotiate their own identities. But in the face of their challenges, their stories also suggest resilience and triumph, as they offer glimpses of the positivity.

Researchers have studied the implications of discrimination and institutional racism on African children (Coe, 2008; Daniel et al, 2005; Kumsa, 2005; Owusu, 1994; Tettey \& Paplampu, 2005; Zaami, 2012) and note that such the social, emotional and psychological repercussion of such negative experiences are note culturally specific, but are experienced 
similarly across cultures. Discrimination and institutional racism can be understood as structural barriers, through systems, policies, practices and discourses in the state and the language and attitudes dominant in the citizenry (Mullaly, 2002).

While the structural barriers did not inform a major part of the dialogue, there were still undercurrents of patriarchy, racism and discrimination within the experiences of the respondents. And it is important to note the significance that such experiences may or may not have on these young women. The narratives suggest that institutional and structural barriers contribute to and compound the identity of immigrant children in migration (Agyekum, 2012; Kobayashi, 2008; Manuh, 1999; Mensah, 2002; Zaami, 2012). In Chapter Five, one of the participants indicated that it was hard to feel good about herself, because of media portrayal of black and African women. Such experiences have the potential to influence their integration into mainstream society. Within their home country, the respondents spoke about structural barriers, along gender roles. Traditionally research on immigrant children/youth focused on the "deficit model" and individualized the problems associated with the adaptation process of immigrant children. But this ignores the structural barriers and the historical context of the individuals themselves and the host country. What is required is emerging research that takes a positivist approach to migration and adaptation of the experiences of immigrant children. While the experiences of the respondents in this study reveal their successful integration, it is clear that we need to investigate the system further to identify the conflicts.

\section{Limitations of the Study}

The issue of Ghanaians in the Diaspora is a complex and multilayered one, which requires a holistic analysis. While this study does not address the various aspects of life in the Diaspora, I have provided an extensive overview of the struggle to sustain and practice cultural 
values, while yet still being a contributing citizen. In saying so, this study is not without its limitations. First, the in-depth interviews used three participants. Considering the growth of the Ghanaian-Canadian community in recent years (Statistics Canada, 2006), this number is a relatively small representation, and as such the findings do not represent the majority of the first and 1.5 and generation. Also, while the study began with an inquest of the 1.5 geners, I used one participant from the first generation population because it became difficult recruiting 1.5 geners; therefore, I cannot generalize the findings as initially intended. Third, as indicated in my methodology, recruitment was to be made through social gatherings, organizations, and institutions. But when efforts generated minimal participants, I used participants from personal contacts and from community churches. This means the views and experiences of those who do not attend church (and other faiths) were not included. This means transferability of the knowledge from this study is limited due to its unintentional exclusion of non-Christian Ghanaians. Considering these limitations, readers should interpret the findings of this study with caution.

\section{Policy Implications and Suggestions for Future Research}

This project provides an overview of the experiences of the first and 1.5 generation Ghanaian-born females in Toronto. In doing so, my aim in this project is that we can begin to study with and understand some of the key issues and concerns of Ghanaian-born females. As a young Ghanaian-born female, I am particularly invested in telling and using these oral narratives as a point of entry into the Ghanaian community in order to better understand their journey and struggles. Due to the fluidity and interconnectedness between and among individuals/groups and cultures, I believe our identity as Ghanaians and Canadians is becoming more important as we live within and between the two cultures. But ultimately, I would like to see the development of 
programs that address the realities of the community at-large, because many of us are growing up in environments that do little to reflect our multitude realities, value systems and histories. Firstly, because the barriers sometimes differ along gender lines, there is the need to carefully examine these barriers from a gender analysis framework. This will help to unearth the major problems young Ghanaian-born females face. And considering the small sample size used in this study, a study based on a larger sample is required to more fully reflect the experiences of the community.

Secondly, there are a number of community organizations who are beginning to address the barriers experienced in the community. As a pioneering member of the Ghanaian Canadian Social Services Network, I have had the privilege of attending a number of community forums and seminars that seek to highlight the barriers and strategies in education and employment. Organizations such as the Ghanaian-Canadian Cultural Association of Ontario, Ghanaian Anglican Church and All Nations Full Gospel Church have initiatives and programs to address such needs. However, the Ghanaian community lacks social services that seek to address some of the concerns discussed in this study: identity, gender politics, race, religion, isolation and structural barriers. Thus, I argue for a discussion and an openness understanding to migratory experiences of young women because existing programs lack the ability to articulate how young Ghanaian-born females are affected by the Ghanaian community's marginalization and the struggles young women face in our communities.

This project is a call and challenge to community leaders, educators and social workers to integrate a holistic analysis of the ways in which young girls and women struggle to challenge expectations within Ghanaian and Canadian cultures. 
Indeed, the perspectives of the young women in this study suggest that extended family is vital to how they perceive and identify themselves. And although the family structure in their current socio-political climate is not reflective of the way they were raised, the participants view this has a natural and necessary component to the composition of life in a Ghanaian household. The discourse on gender politics within Ghanaian household has great implications for the young women who took part in this study. As they try to navigate the complexity of life in the diaspora, they understand that it is a constant negotiation of the ideals of family life and personal goals. It is clear that these participants view themselves as agents with much responsibility, and with the experience of multiple choices with different contexts - Ghanaian traditions, against the backdrop of Canadian culture - neither of which is right nor wrong. With respect to transnational migration, these participants expressed much more certainty about the definition of the situation and their desire to stay connected to their homeland through family ties, social media and financial investments. With regards to religion, the participants view it as being an important practice, because religion in the Ghanaian household is infused with culture and traditional practices, all of which encompass transnational identities. The stories from the participants provide a counter-narrative - that is, the subjugated identity that has defined African women. The voices of these participants echo loudly about their multiple identities, their potential and their agency as both Ghanaian-born women and Canadians. Their quest is to reclaim their lost history (from colonization), culture, self-worth and value.

The concepts discussed in this chapter provide insight into the realities of the participants. This study makes a sophisticated connection between knowledge production and identity, and further complicates this by suggesting that there is a connection between African women, their material lives and the identity they create for themselves. With the task of validating the 
everyday lived experiences of these participants and encouraging open honest dialogue, this study paints a colourful, yet raw account within the Canadian context. The above discussion was an attempt to focus on the nuances of how these women choose to present and structure the self. The following chapter concludes this MRP and will provide an overview of this project, and seek to provide insight into the above discussion and narratives. 


\section{CHAPTER SEVEN: CONCLUSION}

The Ghanaian population in Toronto is a unique community, with an ever growing composition. And although Ghanaians started migrating to Canada as early as the late 1960's to early 1970's, this migration was experienced mostly by scholarship students, professionals working in education, health, and social services, and some political dissidents (Mensah, 2009). But the current trend within Ghanaian migration has witnessed a dramatic increase in the youth demographic (Manuh, 1999; Oppong, 2004). This project is an attempt to situate the experiences of Ghanaian youth in Toronto, specifically the immigrant experiences of Ghanaian-born young women living in Toronto. This inquiry is an investigation into how these young immigrant women navigate tensions between their cultural, ethnic and national identities and loyalties. As noted by Dalby and Ó Tuathail (1998), with the growth of transnationalism, states, economies, and identities have become less territorial than previously, with "forms of life looking increasingly hybrid, flexible, and in transit" (p. 81). While these trends have resulted in considerable economic advantages for some, there remains to be an examination of the personal and cultural implications for others (Massaquoi, 2004; Tettey \& Papulampu, 2005; Wong, 2000). My argument here is that although scholars (Boadi, 2012; Manuh,1999; Opoku-Dapaah, 2006; Owusu 2006) are beginning to examine and address some of the key issues, the personal ramifications of such trends are rarely documented. This project was an attempt to explore how the issues of family, gender, culture, migration and religion play out in Canada, using Ghanaianborn immigrants as a point of reference.

The oral narratives from the participants of this study illustrate well that identity is fluid. I believe the degree of fluidity in identity is a theoretical question, which requires a qualitative methodological exploration and analysis. Using in-depth interviews allowed me to tease out the 
experiential and theoretical understandings of the relationship between ethnic and national identities of these Ghanaian-born young women, while highlighting the similarities between family, gender, culture, race and migration. The bulk of the literature corroborates my findings that the experiences of African women in Canada cannot and should not be lumped into a broad category of the Black experience (Baffoe, 2010; Okeke-Ihejirika \& Spitzer, 2005; Wane, 2007; Yesufu 2005). And even within the African community there exists sub-groups, such as the Ghanaian experience, which looks relatively different from other African communities. But the identity-related concerns raised in this study are not new. We, the community, have a responsibility to create new knowledge about our life histories and hyphenated-identities as Ghanaian-born women. The best way to do this is by letting our voices be heard in all capacities. As a feminist social worker and a Ghanaian-born woman, this project is important for a number of reasons. One, this study is important because of the lack of work on how young immigrant women negotiate our ethnic, cultural and national selves in Canada; it also is significant because it discusses young Ghanaian-born women, a group that has seen limited research consideration in Canada (Wong, 2000). Secondly, this study is important because identity formation among immigrant communities is highly influenced by the level of integration, civic participation, and loyalty in Canada, and ensures that their identities are recognizable, relevant and respected socially, economically and politically. Lastly, this project is significant because transnational identity formation is a vital part of the lives of immigrants in the diaspora, and a closer exploration of such hyphenated-identities provides better insight into our complex realities. The focus on Ghanaian-born females is more than intentional, it is a personal, academic and political response to the invisibility of our identities within the broader Canadian landscape. 


\section{Appendix A-Recruitment Text for Ad and Flyers}

\section{RYERSON \\ UNIVERSITY}

\section{Ghanaian-Born Women Participants Needed for Student Research Study}

Seeking Ghanaian-born women age 18-30 years to volunteer to participate in a research study:

\section{Understanding the integration experiences of young Ghanaian-born women}

Participants will be interviewed and asked a series of questions regarding their experience of migrating from their homeland of Ghana into Canada. Participants will tell their stories of how this migratory process has impacted their lived-experiences within the Canadian education system and general society. The intention of this study is to explore culture, race and gendered implications of Ghanaian-ness and woman-hood. The focus is to explore and understand participants' first-hand accounts of life in Canada. The interview will take place in a private room at Ryerson University, and/or at a private location of participants' preference and convenience.

Wynnie Nketiah, is a student researcher and current social worker, who operates from anti-oppressive and Black-feminist framework. Wynnie is interested in the personal implications of migration and transnationalism, and in particular how transnationalism affects the identities and sense of belonging of Ghanaian-born continental-African women. This is a call for you to tell your story and be heard.

The interview session will be a one-time meeting, and will last an hour and half (1.5hrs). Potential participants can receive a final copy of the findings from the research.

Participants will receive a \$10 gift certificate to Tim Hortons in appreciation for your participation.

To volunteer for this study, please contact:

WynnieNketiah, Masters of Social Work

Ryerson School of Social Work

Email: wnketiah@ryerson.ca

This study has been reviewed and approved by the Ryerson Review Ethics Board, with a duration date from May $15^{\text {th }} 2014$ to Dec 31, 2014 


\section{Appendix B - Email to Community Organizations and Post-secondary institutions}

\section{RYERSON \\ UNIVERSITY}

\section{Ghanaian-Born Women Participants Understanding the integration experiences of young Ghanaian-born women}

Dear Mr. / Ms.

My name is Wynnie Nketiah, a Masters' student conducting this research at Ryerson University, who operates from anti-oppressive and Black-feminist framework. This is an official letter of invitation and recruitment to your members for Ghanaian-born women participants, age 18-30 years to participate in the following research study:

\section{Understanding the integration experiences of Ghanaian-born women}

Participants will be interviewed and asked a series of questions regarding their experience of migrating from their homeland of Ghana into Canada. Participants will tell their stories of how this migratory process has impacted their lived-experiences within the Canadian education system and general society. The intention of this study is to explore culture, race and gendered implications of Ghanaian-ness and woman-hood. The focus is to explore and understand participants' first-hand accounts of life in Canada.

The interview will take place in a private room at Ryerson University, and/or at a private location of participants' preference and convenience. I am writing to ask whether you would be willing to pass along the following information to members who may also be interested in participating and learning about this research study. You are under no obligation to share this information and whether or not you share this information will not affect your relationship with the researcher. This study has been reviewed and approved by the Ryerson Review Ethics Board, with a duration date from May $20^{\text {th }} 2014$ to Dec 31, 2014.

If so, please feel free to forward this email and/or share the attached flyer with members of your organization.

\section{To volunteer for this study, participants can contact: Wynnie Nketiah, Masters of Social Work Ryerson School of Social Work Email: wnketiah@ryerson.ca}

Thank you for your time and consideration.

Sincerely, Wynnie Nketiah 


\section{Appendix C: Demographic Questions}

\section{Section 1: Demographic Profile}

1.How old are you?

O $19-25$ yrs

○ 26-30 yrs

○ 31-35 yrs

○ $36-40 \mathrm{yrs}$

○ 41-45 yrs

2. How old were you when you immigrated?

3. Where was your Mother born? Where was your Father born?

4. Can you describe where you grew up?

a) Where did you spend the majority of your childhood?

5. What is your relationship status?

O Single

O Married

○ Divorced

O Common Law

O Widowed

6. What education have you completed?

○ 8th grade or less

O High School diploma or GED

○ College / Technical Institute diploma

O University degree

O Vocational certification

7. What was your income last year?

○ Less than $\$ 20,000$

○ $\$ 20,000$ to under $\$ 30,000$

○ $\$ 30,000$ to under $\$ 40,000$

○ $\$ 40,000$ to under $\$ 50,000$

O $\$ 50,000$ to under $\$ 60,000$

○ $\$ 60,000$ and over 98 
8. How would you describe yourself?

- Employed - Part time

O Employed - Full time

O Unemployed

O Student

O Retired

Volunteer ( hours per week, on average)

9. What is your current occupation? Could you describe the nature of your job?

10. What is your current living arrangement? (check all that apply)

Live alone

With parent(s)

With friend(s)

O With husband / wife

With partner

$\bigcirc$ With children

With extended family members

11. What best describes your current housing situation?

O Own

○ Rent 


\section{Appendix D: Interview Guide}

\section{Understanding the integration experiences of young Ghanaian-born women}

Preamble: Thank you for agreeing to be part of this research process. Before we start, I would like you to know that this interview will take approximately between 1 and 1.5 hours. I also want to assure you that everything you say here is confidential and that only I will have access to the information you provide, with the exception of my research supervisor. All identifying information will be removed from your transcript and a pseudonym will be used to protect your identity. Before we begin, I would like to ask your permission to record the interview. At any point during the interview, you may ask to stop the recording or take a break. You can also choose to skip any question/s you do not wish to answer, and/or terminate the interview at any point if you feel any discomfort or if you decide to change your mind about being part of this research study. Do you have any questions before we begin?

1. Where did you grow up?

2. Please tell me a bit about your childhood.

3. How old are you?

4. How old were you when you migrated to Canada? Who did you migrate with?

5. Do you have siblings?

a) If so, how many?

b) Did they go through the migration transition with you?

6. Would you identify as Ghanaian. Canadian. Ghanaian-Canadian.

a) why?

7. What does being Ghanaian mean to you?

8. What does being Canadian mean to you?

9. What does Ghana mean to you?

a) Do you have plans to go back to live or visit?

b) why or why not?

10. Did your parents make a conscious effort to teach you about Ghanaian culture?

a) If so, in what ways?

11. Do you belong to any cultural (Ghanaian) associations?

12. Tell me about your experiences growing up as a female in a Ghanaian household?

13. Were they any cultural expectations of you as a Ghanaian female/woman? If so, what were they?

14. What do you think is the biggest lesson you've learned from the women in your family about Ghanaian womanhood? If any?

15. . Where in the GTA did you reside?

16. Did you have contact with other black people?

a) If so, in what setting?

b) What was their cultural background?

c) How did you relate or not relate to them?

17. What are some of the issues you see young Ghanaian women going through, specifically within Canada? 
18. In terms of identity struggles, what type of resources do you think would be useful for Ghanaian youth in the Toronto area, and GTA?

19. I wanted to thank you for this. Is there anything else you wanted to add just before we wrap up? Anything I didn't ask about that you think is important? Do you have any questions for me? 


\title{
Appendix E-Consent Form
}

\section{RYERSON}

UNIVERSITY

\section{CONSENT TO PARTICIPATE IN RESEARCH}

\author{
SCHOOL OF SOCIAL WORK \\ FACULTY OF COMMUNITY SERVICES \\ Accredited by The Canadian Association for Social Work Education
}

Understanding the integration experiences of young Ghanaian-born women

You are being invited to participate in a research study. Please read this Consent Form so that you understand what your participation will involve. Before you consent to participate, please ask any questions necessary to be sure you understand what your participation will involve.

\section{INVESTIGATOR:}

This research study is being conducted by Wynnie Nketiah in partial fulfillment of a Master's degree in Social Work under the supervision of Dr. Susan Preston.

If you have any questions or concerns about the research, please feel free to contact Supervisor: Wynnie or her supervisor Susan Preston, PhD Associate Professor, Ryerson School of Social Work at s2presto@ryerson.ca or 416-979-5000 ext 6218.

\section{PURPOSE OF THE STUDY}

This project has three main objectives. Firstly, through an exploration of the realities of second-generation Ghanaian-born women and their identity formation, I want to challenge popular ideas about what it means to be Black in Canada. This is because for a long time, the majority of the Canadian population has assumed that all people in Black communities in Canada are from the Caribbean, and I want to try to challenge this idea by focusing on the unique experiences of Ghanaian-born women living in Canada. Secondly, I start this project as a way to think through my own (Ghanaian) community's current concerns in Canada, mostly young women's struggles with identity within a larger Canadian society, as well as their own family's cultural expectations of Ghanaian womanhood. Lastly, as an African woman student, I believe I have a duty to expose some of the issues and concerns from an African woman's viewpoint, and do it responsibly. 


\section{DESCRIPTION OF THE STUDY AND YOUR PARTICIPATION}

As a participant of this interview, you agree to be interviewed by Wynnie Nketiah, a student in the Masters of Social Work program at Ryerson University, whose work is being supervised by Susan Preston. The purpose of the personal interviews is to discuss how you, as Ghanaian women living in the Toronto area, make sense of your identities within a multicultural context. Participants will be interviewed and asked a series of questions regarding your experiences of migrating from your homeland of Ghana into Canada and living in Canada. As a participant, you will be encouraged to tell your stories of how this process of migrating has impacted your life within the Canadian education system and general society. The interview will take place in a private room at Ryerson University campus or in a location of your preference. The interview session will be a one-time meeting, and will last an hour and half (1.5hrs). You can receive a final copy of the findings from the research if you wish.

\section{Risks or Discomforts}

The risks of this study are minimal. You are fully aware that these conversations are being audio-recorded and will be later transcribed for the researcher's major research project. In regards to personal and individual interviews, participant information will be remain confidential, except if you share something about harming yourself or someone else. To protect the confidentiality of participants no names will be used so that all identities will remain confidential. Participants can choose a pseudonym or one will be assigned for them in my Major Research Project to ensure that no one can be identified. All information that you provide is voluntary and you may wish to refrain from answering particular questions. You might experience discomfort during the interview because of the length or because of the emotional nature of the discussion. Please note that you can stop the interview, take a break, or withdraw at any point during the interview process or after it has taken place. If you decide to withdraw before my final research is submitted to my supervisor, all data collected from you will be destroyed and will not be included in the study. Participants will have rights to review and edit your recordings or transcripts should you choose.

Also, your identity will be protected before, during or after the interview to the best of the researcher's ability. Both transcribed interviews and audio-recordings will be used until December 31, 2014. After this time, I will keep copies of the audio recording in a locked drawer in my home for another three months and then it will be destroyed. The written documents will be shredded and disposed at this time as well.

Lastly, at the end of the personal interviews, I will leave all participants with my contact card, as well as my supervisor's (Susan Preston) contact information and an information sheet about support and other community services. Please note that no follow up sessions will be required, and you are only required to attend this one interview session. Also note that participants' decision whether or not to participate in this study will not influence relations with the researcher and/or Ryerson University. 


\section{Benefits}

Participants may benefit by gaining insight into their lived experience. After the findings have been published, the population may benefit by acknowledging that others have similar experiences, which may validate their experiences and lessen the feelings of isolation that immigrants often experience. At the society level, this study can help to challenge what is commonly perceived about immigrants (more specifically young Ghanaian-born women). The study may also help to challenge dominant knowledge by highlighting the unique experiences of participants. The study may also benefit the Ghanaian-Canadian community by providing data for future studies, policies and the formation of community programs.

Henceforth, it is assumed that all participants are aware of the aforementioned expectations of this study.

\section{things:}

If you volunteer to participate in this study, you will be asked to do the following

- Attend a one and a half hour interview session at Ryerson University or location of your choice.

- Participate in a one-time, interview

- Participants will be asked questions like these:

1. How old were you when you migrated to Canada?

2. How old are you now?

3. How would you identify? Would you identify as Ghanaian? Canadian? Ghanaian-Canadian?

4. What does being Ghanaian mean to you?

5. What does Ghana mean to you? and Do you have plans to go back to live or visit? And why or why not?

\section{Incentive to participate}

Participants will receive a $\$ 10$ gift certificate to Tim Hortons in appreciation for your participation. No other payment will be made to participants in this study.

QUESTIONS ABOUT THE STUDY

If you have any questions about the research now, please ask. If you have questions later about the research, you may contact:

Wynnie Nketiah (MSW Student)

wnketiah@ryerson.ca

\section{Study Supervisor:}

Susan Preston- (416) 9795000 x6218

s2presto@ryerson.ca 
This study has been reviewed by the Ryerson University Research Ethics Board. If you have questions regarding your rights as a research participant in this study, please contact:

\author{
Toni Fletcher, Research Ethics Coordinator \\ Research Ethics Board \\ Office of the Vice President, Research and Innovation \\ Ryerson University \\ 350 Victoria Street \\ Toronto, Ontario M5B 2 K3 \\ 416-979-5042 or toni.fletcher@ryerson.ca
}

\title{
SIGNATURE OF RESEARCH PARTICIPANT/LEGAL REPRESENTATIVE
}

Your signature below indicates that you have read the information in this agreement and have had a chance to ask any questions you have about the study "Understanding the Integration Experience of Ghanaian-born women" as described herein. Your questions have been answered to your satisfaction, and you agree to participate in this study. You have been given a copy of this form.

\footnotetext{
Name of Participant (please print)

Signature of Participant
}

Date

Please indicate by providing your signature below that you have been informed and agree to being audio recorded.

$\overline{\text { Signature of audio recorded Participant }}$ 


\section{Appendix F: Counselling and Community Resources}

Access Alliance Multicultural Health and Community Services

761 Jane St, 2nd Fl, Ste 200B

Toronto, ON

M6N 4C4

Tel: 416-760-8677

COSTI - North York Centre - Family and Mental Health Services

Sheridan Mall

1700 Wilson Ave, Ste 105

Toronto

Tel: 416-244-7714

East York Mental Health Counselling Services Agency

1245 Danforth Avenue

Toronto, ON

M4J $1 \mathrm{M} 8$

info@alternativestoronto.org

Family Service Toronto (Walk-in Counselling)

355 Church St

Toronto, ON

M5B 1 Z8

Tel: Service Access Unit 416-595-9618

Rexdale Women's Centre - Support for Women and Families

925 Albion Road, Ste 309

Etobicoke, ON

M9V $1 \mathrm{~A} 6$

Tel: 416-745-0062

Tropicana Community Services

670 Progress Ave, Ste 14-16

Scarborough, ON

$\mathrm{M} 1 \mathrm{H} 3 \mathrm{~A} 4$

416-439-9009

Women's Health in Women's Hands Community Health Centre

2 Carlton St, Ste 500

Toronto, ON

M5B $1 \mathrm{~J} 3$

416-593-7655 


\section{References}

Adichie, C. (2014). We should all be feminist. London, England: Anchor Books.

Aidoo, A. (1992). Changes: A love story. New York: The Feminist Press.

Agyekum, B. (2012). The Second Generation and the Labour Market: The case of

Ghanaian-Canadians in Toronto. (Unpublished Master's thesis). York University.

Amenga-Etego, R. M. (2012). Gender and Christian spirituality in Africa: A Ghanaian perspective. Black Theology: An International Journal, 10(1), 8-27.

Appiah, A. (2005). The ethics of identity. New York: Princeton University Press.

Asante, M. K. (2005). African aesthics. In M. Asante \& A. Mazama (Eds), Encyclopedia of Black Studies. (pp.6-18). Thousand Oaks, CA: Sage Publications.

Baffoe, M. (2010). The social reconstruction of "home" among African immigrants in Canada. Canadian Ethnic Studies, 41(3), 157-173.

Baines, D. (2011). An overview of anti-oppressive practice: Roots, theory and tensions.

In D. Baines \& K. Smith (2nd ed.), Doing anti-oppressive practice: Social justice social work (pp. 10-26). Toronto: Fernwood Publishing.

Bell, D. (1973). Race, Racism and American Law. New York, NY. Little Brown \& Co.;

Bell, D. (2008). Race, Racism and American Law (6th ed). New York, NY. Little Brown $\&$ Co.

Bell, D. (1992). Faces at the bottom of the well. New York: Basic Books.

Bell, D. (2004). Silent Covenants: Brown v. Board of Education and the Unfulfilled Hopes for Racial Reform. New York, NY. Oxford University Press. 
Blay, Y. A. (2008). All the "africans" are men, all the "sistas" are "american," but some of us resist: Realizing african feminism(s) as an africological research methodology. Journal of Pan African Studies, 2(2), 58-73.

Bankston, C.L. \& Zhou, M. (1996). The ethnic church, ethnic identification, and the social adjustment of Vietnamese adolescents. Review of Religious Research. 38, 18-37 1996).

Breton, R. (2012). Different gods: Integrating non-christian minorities into a primarily christian society. McGill-Queen's University Press.

Bloemraad, I. (2004). Who claims dual citizenship? The limits of postnationalism, the possibilities of transnationalism and the persistence of traditional citizenship. The International Migration Review, 38 (2): 389-426.

Bosniak, Linda (2003). Multiple nationality and the postnational transformation. In D. Martin \& K. Hailbronner (Eds.) Rights and Duties of Dual Nationals: Evolution and Prospects (p p. 27-48). Hague: Kluwer Law International.

Boyce, C., \& Neale, P. (2006). Conducting in-depth interviews: A guide for designing and conducting in-depth interviews for evaluation input. Watertown, MA: Pathfinder International.

Boyce-Davies, Carole. (1994). Black Women, Writing and Identity: Migrations of the Subject. New York: Routledge.

Charmaz, K. (2012). Grounded theory methods in social justice research. In N. Denzin \& Y. Lincoln (Eds). The sage handbook of qualitative research $\left(3^{\text {rd }} \mathrm{ed}\right.$, pp. 359-380). Thousand Oaks, CA: Sage Publications. 
Chuang, S. S., \& Moreno, R. P. (2011).Changing lives: Theoretical and methodological advances on immigrant children and youth. In S. Chaung \& R. Moreno (Eds). Immigrant children: Change, adaptation, and cultural transformation. (pp. 1-6). Maryland: Lexington Book.

Clandinin, D. J., \& Huber, J. (2010). Narrative inquiry. In B. McGraw, E. Baker, \& P.Peterson (Eds.), International encyclopedia of education. (pp. 436-441). New York, NY: Elsevier.

Clavin, P. (2005). Defining transnationalism. Contemporary European History, 14(4), 421-439.

Coe, C. (2008). The structuring of feeling in Ghanaian transnational families. City \& Society, 20(2), 222-250.

Coll, G., \& Marks, A. K. (2012). The immigrant paradox in children and adolescents: Is becoming American a developmental risk? American Psychological Association.

Cortazzi, M. (1993). Narrative Analysis. New York, NY. Routledge Falmer Press.

Creese, G. L. (2011). The new African diaspora in Vancouver: migration, exclusion, and belonging. Toronto, ON: University of Toronto Press.

Crenshaw, K. (1995). Mapping the margins: Intersectionality, identity politics and violence against women of color. In K. Crenshaw, N. Gotanda, G. Peller \& K. Thomas (Eds), Critical race theory: The key writings that formed the movement. (pp. 357-496). New York: New York Press.

Creswell, J. (2007). Five different qualitative studies. In J. Creswell (Ed), Qualitative inquiry and rsearch design: Choosing among five approaches. (pp. 111-177). Thousand Oaks, CA: Sage Publication, Inc. 
Crooks, D.L. (2001). The importance of symbolic interaction in grounded theory research on women's health. Healthcare for women international, 22(1-2), 11-27.

Cudjoe, H. (2005). Africa(ns) in the educational system: An analysis of positionality knowledge construction. In W. Tettey, \& K. Puplampu (Eds), The African diaspora in Canada: Negotiating identity and belonging (pp. 63-85). Calgary: University of Calgary Press.

Dalby, S., \& Toal, G. (1998). Rethinking geopolitics. New York: Routledge.

Daniel, B, Feather-Stone, B., Hooper, C. \& Scourfield, J. (2005). Why gender matters for Every Child Matters. British Journal of Social Work 8(35), 1343-355.

Davis, A. (1981). Women, Race and Class. New York: Random House.

Davis-Sowers, R. (2012). It just kind of like falls in your hands: Factors that influence Black aunts' decisions to parent their nieces and nephews. Journal of Black Studies, 43(3), 231250.

Dei, G. (1997). Reconstructing 'dropout': A critical ethnography of the dynamics of Black students' disengagement from school. Toronto, ON: University of Toronto Press.

Delgado, R. (1989). Storytelling for oppositionists and others: A plea for narrative. Michigan Law Review, 87(8), 2411-2441.

Delgado, R., Stefancic, J., \& Harris, A. (2012). Critical race theory: An introduction (2nd ed.). New York University Press.

Donkor, Martha. (2000). The education of immigrant women: prospects and challenges for Ghanaian Immigrant women in Canada. (Unpublished doctoral thesis). University of Toronto).

Dominelli, L (2002). Feminist Social Work Theory and Practice. New York, NY: Palgrave. 
DeCuir-Gunby, J. T., Marshall, P., \& McCulloch, A. (2011). Developing and using a codebook for the analysis of interview data: An example from a professional development research project. Field Methods, 23(2), 136-155.

Ebaugh, H. R. F., \& Chafetz, J. S. (2000). Religion and the new immigrants: Continuities and adaptations in immigrant congregations. New York: AltaMira Press.

Fine, M. (1994). Working the hyphens: Reihnventing self and other in qualitative research. In N. Denzin \& Y. Lincoln (Eds). The sage handbook of qualitative research $\left(3^{\text {rd }} \mathrm{ed}\right)$. (pp. 70-82). Thousand Oaks, CA: Sage Publications.

Firang, D.F. (2011). Transnational Activities and Their Impact on Achieving a Successful Housing Career in Canada: The Case of Ghanaian Immigrants in Toronto. (Unpublished doctoral dissertation). University of Toronto.

Fitzgerald, T. (2004). Powerful voices and powerful stories: Reflections on the challenges and dynamics of intercultural research. Journal of Intercultural Studies, 25 (3), 233-245.

Floersch, J., Townsend, L., Longhofer, J., Munson, M., Winbush, V., Kranke, D. Findling, R. L. (2009). Adolescent experience of psychotropic treatment. Transcultural Psychiatry, 46(1), 157-179.

Foucault, M. (1980). Truth and power. In C. Gordon (Ed), Power/knowledge: Selected interviews and other writings, 1972-1977 (pp. 110-121). New York: Pantheon Books.

Gariba, S. (2009). Race, ethnicity, immigration, and jobs: labour market access among Ghanaian and Somali youth in the Greater Toronto Area. (Unpublished Master's thesis). University of Toronto).

Gee, J. P. (2005). An introduction to discourse analysis: Theory and method (2nd ed.). New York: Routledge. 
Ghanaian Coalition of Young Professionals Conference. (2009). Putting Things into Context: Facilitating the success of Ghanaian youth in Canada and providing a regenerating source for community advancement. Toronto, ON: K. Achampong.

Glaser, B., \& Strauss, A. (1967). The discovery of grounded theory: Strategies for qualitative research. New York, NY: Aldine Press.

Gurbrium, J and Holstein, J. (2000). The Self We Live By: Narrative Identity in a Postmodern World. New York, NY: Oxford University Press Inc.

Hawkesworth, M. E. (1989). Knowers, knowing, known: Feminist theory and claims of truth. Signs, 14(3), 533-557.

Heron, J., \& Reason, P. (2006). The practice of co-operative inquiry: Research 'with' rather than 'on' people. In J. Heron \& P. Reason (Eds), Handbook of action research. (pp.44154). London: Sage Publications.

Henry, M. (2007). If the shoe fits: Authenticity, authority and agency feminist diasporic research. Women's Studies International Forum, 30 (1), 70-80.

Herman, L. (2005). Handbook of Narrative Analysis. Lincoln: University of Nebraska Press.

Hill-Collins, P. H. (1986). Learning from the outsider within: The sociological significance of black feminist thought. Social Problems, 33(6), S14-S32.

Hill-Collins, P. (2000). Black feminist thought: Knowledge, consciousness, and the politics of empowerment (Rev. 10th anniversary ed.). New York: Routledge.

hooks, b. (1981). Ain't I a woman: Black women and feminism South End Press.

hooks, b. (2000). Sisterhood: Political solidarity among women. Feminist theory: From margin to center (2nd ed). Cambridge, MA: South End Press. 
George, P. (2012) Hou, F., \& Coulombe, S. (2010). Earning Gaps for Canadian-Born Visible Minorities in the Public and Private Sectors. Canadian Public Policy 36 (1): 29-43. Humphrey, C. (2007). Insider-outsider: Activating the hyphen. Action Research, 5, (1), 11 .

Igoa, C. (1995). The inner world of the immigrant child. New York: St. Martin's Press. Jejunum. (2003). In Merriam-Webster's dictionary (11th ed.). Springfield, MA: MerriamWebster.

Kitson, E. (2003). Rethinking gender relations: The micro politics within the Ghanaian immigrant households in metropolitan Toronto. (Unpublished Thesis). York University.

Kobayashi, A. (2008) A research and policy agenda for second generation Canadians. Canadian Diversity, 6(23): 3-6.

Kumsa, M. K. (2005). Between home \& exile: Dynamics of negotiating belonging among young Oromos living in Toronto. In Tettey, W., \& Puplampu, K. P. (Eds.). The african diaspora in Canada: Negotiating identity \& belonging (pp. 175-196). Calgary: University of Calgary Press.

Kvale, S. (2007). Doing Interviews. Thousand Oaks, CA: Sage Publishing. Labov, W. (1997). Some further steps in narrative analysis. Journal of narrative and life history, 7(1), 395-415.

Ladson-Billings, G., \& Tate, W. F., IV. (1995). Toward a critical race theory of education. Teachers College Record, 97(1), 47-68.

Ladson-Billings, G. (1998). Just what is critical race theory and what's it doing in a nice field like education? International Journal of Qualitative Studies in Education, 11(1), 7-24. 
Langout, R. D. (2006). Where am I? locating myself and its implications for collaborative research. American Journal of Community Psychology, 37(3-4), 267-274.

Langhout, R. D. (2003). Racialized discourses and ethnic epistemologies. In Denzin, N. K., \& Lincoln, Y. S. (2000). Handbook of qualitative research (2nd ed.). Sage Publications.

Manuh, Takyiwaa (1999). This Place is not Ghana: Gender and Rights Discourse among Ghanaian Migrants in Toronto, Canada. Ghana Studies Journal 2: 77-9.

Massaquoi, N. (2007). Introduction: Future Imaginings of Black Feminist Thought. In N. Massaquoi, \& N. Wane (Eds.), Theorizing Empowerment: Canadian Perspective on Black Feminist Thought. (pp.5-26). Toronto, Canada: Inanna, York University.

Massaquoi, N. (2007). An Unsettled Feminist Discourse. In N. Massaquoi, \& N. Wane (Eds) Theorizing Empowerment: Canadian Perspective on Black Feminist Thought. 75-94. Toronto, Canada: Inanna, York University.

Matei, S.A. \& Dobrescu, C. (2011). Wikipedia's "neutral point of view": Settling conflict through ambiguity. The Information Society, 27(1):40-51.

Matsuda, M. J. (1993). Words that wound: Critical race theory, assaultive speech, and the first amendment. New York: Westview Press.

Mekgwe, P. (2008). Theorizing African feminism(s): The 'colonial' question. Matatu Journal for African Culture and Society, 35(1), 165-174.

Mensah, Joseph. (2002). Black Canadians: History, Experiences and Social Conditions. Halifax: Fernwood Publishing.

Mensah, J. (2009). 'Doing Religion' Overseas: The Characteristics and Functions of Ghanaian Immigrant Churches in Toronto, Canada. Societies Without Borders 4 (1): 21-44. 
Mishler, E, G. (1995). Models of narrative analysis: A typology. Journal of Narrative \& Life History, 5(2), 87-123.

Mohanram, R. (1999). Black body. Women, colonialism, and space. Minneapolis and London: University of Minnesota Press.

Mohanty, C. (2003). Feminism without Borders: Decolonizing Theory, Practicing

Solidarity. Durham, N.C: Duke University Press.

Mullaly, B. (2002). Challenging Oppression: A Critical Social Work Approach. Oxford University Press. Toronto.

Norris, A B. J.,Harrington, D,. Grossman, M., Hemed, \& Hindin, M. (2016). Abortion experiences among Zanzibari women: a chain-referral sampling study. Reproductive Health 13, p. 23-33.

Obioma, N. (1998). Introduction: Reading the Rainbow. In N. Obioma (Eds). Sisterhood, Feminisms \& Power From Africa to the Diaspora (pp.1-35). Trenton, NJ: Africa World Press.

Obioma, N. (2005). Mapping African Feminisms. In A. Cornwall (Eds). Readings in Gender in Africa. (pp.31-39). Bloomington, Indiana: Indiana University Press.

Oduyoye, M. (2001). Introducing African Women's Theology. Sheffield: Sheffield Academic Press.

Okeke-Ihejirika, P., \& Spitzer D.L. (2005). In Search of Identity: Intergenerational Experiences of African Youth in a Canadian Context. In W. J. Tettey and K. P. Puplampu (Eds). The New African Diaspora in Canada: Negotiating Identity and Belonging. (pp.2-23). Calgary: University of Calgary.

Oktay, S. (2012). Grounded Theory. New York: Oxford University Press. 
Opoku-Dapaah. (2006). African Immigrants in Canada: Trends, Socio-demographic and Spatial Aspects. In K. Konadu-Agyemang, B. Takyi, and J. Arthur (Eds), The New African Diaspora in North America. (pp.69-94). Toronto: Lexington Books.

Oppong, J. (2004)). “Internal, international and transnational migraton.” In M. TotoMorn and M. Alicea (Eds). Migration and immigration: A global view. (pp. 81-93). Westport, CT: Greenwood Press.

Owusu, T. (1994). The adaptation of black African immigrants in Canada: A case study of residential behaviours and ethnic community formation among Ghanaians in Toronto. University of Toronto. Toronto: OISE University of Toronto.

Owusu, T. (2006). Transnationalism among African immigrants in North America: The case of Ghanaians in Canada. In K. Konadu-Agyemang, B. Takyi, \& J. Arthur (Eds.), The new African diaspora in North America: Trends, community building, and adaptation (pp. 273 286). New York, NY: Lexington Books.

Padgett, D. (2008). Qualitative methods in social work research. Los Angeles, Calif: Sage Publications.

Patton, M. Q. (2002). Qualitative research and evaluation methods ( $3^{\text {rd }}$ ed.). Thousand Oaks, CA: Sage.

Postmes, T. \& Branscombe, N. (2010). Sources of social identity. In T. Postmes \& N. Branscombe (Eds). Rediscovering Social Identity: Core Sources. (pp.15-28). New York: Psychology Press.

Potts, K \& Brown, L (2005). Becoming an anti-oppressive researcher. In L. Brown \& S. Strega (Eds.), Research as Resistance (pp. 255-286). Toronto: Canadian Scholars' Press. 
Reyez-Cruz, M. (2008). What if I just cite Grasiela: Working toward decolonizing knowledge through a critical ethnography. Qualitative Inquiry, 14(4), 651-658.

Riessman, C.K. (1993). Narrative Analysis. Qualitative research methods. Newbury Park, California: Sage Publishing.

Riessman, C. K. (2008). Narrative methods for the human sciences. Thousand Oaks, CA: Sage Publishing.

Rubbin, A., \& Babbie, E. (2008). Research methods for social work ( $7^{\text {th }}$ ed). Belmonte, CA: Brooks/Cole Cengage Learning.

Rumbaut, R \& Portes, A. (2001). Ethnogenesis: Comingo of age in immigrant America. In R. Rumbaut \& A. Portes (Eds). Ethnicities: children of immigrants in America.(pp.1-16). Berkeley, CA: University of California Press.

Rumbaut, R. (2004). Ages, life stages and generational cohorts: Decomposing the immigrant first and second generations in the United States. International Migration Review, 38(3), 1160-1205..

Sbaraini, A., S. Carter1., R Wendell Evans., \& A, Blinkhorn. (2011). How to do a grounded theory study: a worked example of a study of dental practices. Medical Research Methodology. 11(11), 128-138.

Schreiber, L. (2000). Overcoming methodological elitism: Afrocentrism as a prototypical paradigm for intercultural research. International Journal of Intercultural Relations. 24(5), 651-671.

Sherry, M, (2008). Insider-Outsider status. In L. Given (Ed.) .The Sage encyclopedia of qualitative research methods. (pp. 433-434). Thousand Oaks, CA: Sage Publications. 
Solorzana, D (1998). Critical race theory, race and gender microaggressions, and the experience of Chicana and Chicano scholars. Qualitative Studies in Education. 2(1). 121-136..

Solorzano, D. G., \& Yosso, T. J. (2001). Critical race and LatCrit theory and method: Counter-storytelling. International Journal of Qualitative Studies in Education, 14(4), 471-495.

Solórzano, D. G., \& Yosso, T. J. (2002). Critical race methodology: Counter-storytelling as an analytical framework for education research. Qualitative Inquiry, 8(1), 23-44.

Smith, T. (1978). Religion and Ethnicity in America. American Historical Review $83: 1155-85$.

Statistics Canada. (2001) National Census of Canada, Ottawa: Statistics Canada. Statistics Canada. (2008). Group differences in educational attainment among the children of immigrants. (Analytical Studies Branch). Toronto, ON. T. Abada \& F. Hou, B. Ram. Statistics Canada. (2011). National Census of Canada, Ottawa: Statistics Canada. Strauss, A., \& Corbin J. (1990). Grounded theory research: Procedures, cannons and evaluative criteria. Qualitative Sociology, 13(1), 418-427.

Strauss, A., \& Corbin J. (1994). Grounded theory methodology: An overview. In N. Denzin, \& Y. Lincoln (Eds.), Handbook of qualitative research (pp. 273-285). Thousand Oaks, CA: Sage Publications.

Taiwo, O. (2003). Feminism and Africa: Reflections on the Poverty of Theory. In O. Oyewumi (Eds), African Women \& Feminism: Reflecting on the Politics of Sisterhood (pp.4566). Trenton, NJ Africa World Press.

Tegomoh, E. (2002). Experiencing African Feminisms. Agenda, 17 (54), 113-121.. Tettey, W., \& K. Puplampu. (2005). Continental Africans in Canada: Exploring a neglected dimension of the African-Canadian experience. In W. Tettey, \& K. Puplampu (Eds.), The 
African diaspora in Canada: Negotiating identity and belonging (pp.2-23). Calgary, AB: University of Calgary Press.

Thiong'o, Ngugi wa. (2007). Writing Against Neo-Colonialism. In A. Olaniyan and A. Quayson (Eds). African Literature: An Anthology of Criticism and Theory (157-168). Victoria, Austrailia: Blackwell Publishing.

Thomas, G. \& James, D. (2006). Reinventing grounded theory: some questions about theory, ground and discovery. British Educational Research Journal, 32, 6, 767-795..

Timothy, R K. (2007). Third World, 'Women of Colour', and 'Minority Women': An African/Black Feminist Analysis of Our Identities. In N. Massaquoi, \& N. Wane (Eds.), Theorizing Empowerment: Canadian Persepctives on Black Feminist Thought. (155172).Toronto, ON: Inanna Publications and Education.

Vertovec, Steven. (1999). Conceiving and researching transnationalism. Ethnic and Racial Studies. 22 (2), 447-462.

Wallace, Michelle. (1979). Black Macho and the Myth of the Superwoman. London: The Dial Press.

Wane, N. (2007). African women and Canadian history: Demanding our place in the curriculum. In N. Massaquoi, \& N. Wane (Eds.), Theorizing empowerment: Canadian perspective on Black feminist thought (pp.129-154). Toronto, ON: Inanna Publication.

Wayland, S. V. (2006). The Politics of Transnationalism: Comparative Perspectives. In Vic Satzewitch and Lloyd Wong (Eds.) Transnational Identities and Practices in Canada. (pp. 18-34). Vancouver: UBC Press.

West, C. (1992, ). Learning to talk of race. New York Times Magazine, 24, 26. New York. 
Wuest, J \& Merritt-Gray, M. (2001). Feminist grounded revisited: Practical issues and new understandings. In Schreiber, R., \& Stern, P. N. Using grounded theory in nursing. (pp.159172). New York: Springer Pub. Co.

Williams, P. (1991). The alchemy of race and rights : Diary of a law profess or. Cambridge, MA: Harvard University Press.

Wong, M (2000). Ghanaian women in Toronto's labour market: Negotiating gendered roles and transnational household strategies._Canadian Ethnic Studies Journal, 32(2), 45-76.

Yesufu, Adenike. (2005). The Case of African-Canadian Women in Edmonton. In W. Tettey and K. Puplampu (Eds). The New African Diaspora in Canada: Negotiating Identity and Belonging. (pp.133-146). Calgary: University of Calgary.

Zaami, M. (2012). Experiences of Socio-Spatial Exclusion among Ghanaian Immigrant Youth in Toronto: A Case Study of the Jane-Finch Neighborhood. Electronic Thesis and Dissertation Repository. London, ON: University of Western. 